\title{
Prolific Domains and the Left Periphery ${ }^{*}$
}

\author{
Kleanthes K. Grohmann \\ University of Maryland \\ grohmann@wam.umd.edu
}

\section{Introduction}

The left periphery has enjoyed extensive study over the past years, especially drawn against the framework of Rizzi (1997). It is argued that in this part of the clause, relations are licensed that have direct impact on discourse interpretation and information structure, such as topic, focus, clause type, and the like. I take this line of research up and argue in favour of a split CP on the basis of strictly left-peripheral phenomena across languages. But $I$ also want to link the relation of articulated clause structure, syntactic derivations, and information structure. In particular, I outline the basics of a model of syntactic derivation that makes explicit reference to the interpretive interfaces in a cyclic, dynamic manner.

I suggest a return to older stages of generative grammar, at least in spirit, by proposing that clausal derivation stretches over three important areas which $I$ call prolific domains: the part of the clause which licenses argument/thematic relations ( $V$ - or $\theta$-domain), the part that licenses agreement/grammatical relations ( $\mathrm{T}$ - or $\phi$-domain), and the part that licenses discourse/information-relevant relations (C-or $\omega$-domain). It is thus a rather broad and conceptual notion of ,adding“ and „omitting“ that I am concerned with here, namely licensing of material to relate to information structure, and the desire to find an answer to the question which elements might be added or omitted across languages to establish such links.

On a more programmatic note, one corollary of the proposal made here is the design of dynamic derivations which we can visualize roughly in (1) below.

Central to the notion of prolific domain as developed here is the condition that any given maximal phrase XP find a unique address in (at most) each of these domains. An address denotes the point of interpretation at the interfaces; informally speaking, this condition restricts occurrence of any given XP to one and only one position per domain. Derivations are constructed over domains. Implementing the notion of ,multiple Spell Out" (Uriagereka 1999), I propose that the relevant pieces of information are shipped to the interfaces (ultimately, LF and PF) each time a domain is established. This suggests a modification of the standard $T$-model well-known from principles and parameters frameworks such as in (1), where the levels of PF and LF are fed successive-cyclically.

I am grateful to the audiences in Konstanz, Vienna, Santa Cruz, Philadelphia and Minneapolis where I presented parts of this paper. The following friends deserve many thanks for listening to my ramblings, commenting on the material, and/or reading various parts of the manuscript: Artemis Alexiadou, Joseph Aoun, Jonathan Bobaljik, Cedric Boeckx, Juan Carlos Castillo, Barbara Citko, John Drury, Norbert Hornstein, Ewald Lang, Anoop Mahajan, André Meinunger, Dominique Sportiche, Tim Stowell, Juan Uriagereka, Chris Wilder, Susi Wurmbrand, Jan-Wouter Zwart. Last, but not least, thanks to the organizers for a great A\&O-workshop. I acknowledge support from a DFG-scholarship and NSF grant SBR9601559. The usual disclaimers apply. 


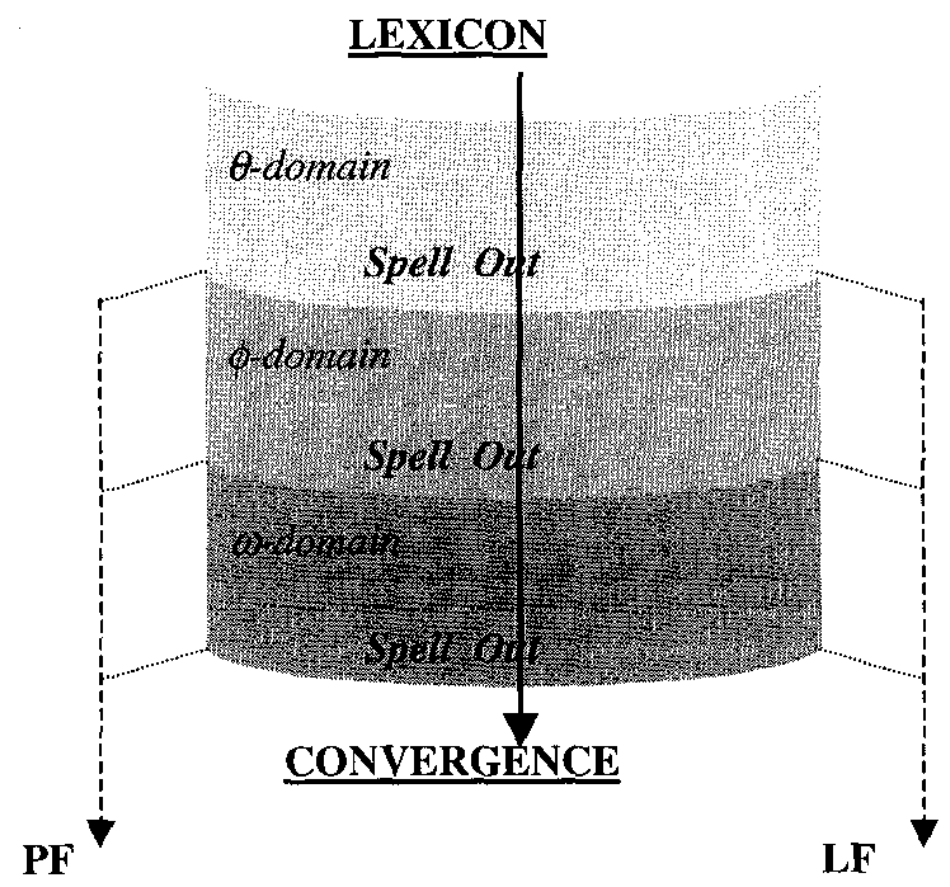

\section{Movement issues in left dislocation constructions}

I start out by comparing similar looking instances of left dislocation in German where I present arguments to the extent that the two constructions not only are different on the surface, they also differ with respect to their syntactic derivation and landing sites.

\subsection{Two types of left dislocation}

At first glance, German seems to make available a number of syntactic forms that serve roughly the same discoursal function: a left-dislocated phrase, picking up a contextual topic of sorts, is resumed by a pronominal element. ${ }^{\text {I }}$ The various alternatives simply seem to differ with respect to the position and form of the resumptive element, as well as in Case-matching between the left-dislocated phrase and the resumptive.

Some relevant instances of left dislocation are shown in $(2):^{2}$
Wagen, den
hat Peter
gestern
verkauft.
the-ACC car
that-ACC(RP) has Peter
yesterday
sold
b. Der
Wagen, den
hat Peter
gestern
verkauft.
the-NOM car
that-ACC(RP) has Peter
yesterday
sold

\footnotetext{
I only consider the syntactic properties of left dislocation. For discoursal licensing of the different types, see Gundel (1974), Altmann (1981), Birner \& Ward (1998), Prince (1998), Grabski \& Frey (2000), and others.

2 Not all orders in (2) are equally felicitous in all contexts, and further variations of HTLD can be construed. I also leave out further discussion regarding possible sub-divisions of HTLD, the impact of prosody, stress or intonation and related issues.
} 


c. Der Wagen, Peter hat ihn gestern
the-NOM car Peter has that-ACC(RP) yesterday sold
'The car, Peter sold (it) yesterday.'

In (2a), the left-dislocated constituent and the resumptive pronoun match in Case, the resumptive is in high position, and it comes in the form of the demonstrative pronoun. Their referential identity is indicated through italics, and in addition, the resumptive is boldfaced; following standard convention, I refer to the resumptive as $d$-pronoun. There are good reasons to believe that the $d$-pronoun is in topic position and thus satisfies the verb second requirement of German matrix clauses. In this sense, the left-dislocated element seems to be outside the clause to some extent (or else, verb second were violated). A similar construction can be found in Icelandic which prompted Thráinsson (1979) to dub it ,contrastive left dislocation“ (CLD), a term that shall play no further role (but see Grohmann 2000a).

In (2b) and (2c), the two elements in question do not agree in case; the left-dislocated phrase is marked nominative (but can optionally match in Case with the resumptive; see Altmann 1981 for quite accurate characterization). Moreover, the resumptive can appear in either topic position or in the usual surface position of DP-arguments (presumably, its Case position), and it can surface as $d$ - or $p$ (ersonal)-pronoun. This construction is also known as nominativus pendens or "hanging topic left dislocation" (HTLD).

That the two constructions differ syntactically has already been argued in the literature at various times (e.g., van Riemsdijk \& Zwarts 1974, Vat 1977, van Haaften et al. 1983, Grohmann 1997, van Riemsdijk 1997). We could say that the evidence comes in two flavours: one definitely relates to connectedness effects in CLD, which one could expect, given the observed Case-matching; the other contains diagnostics for movement independent of such reconstruction effects, which furthermore indicate what kinds of operations might underlie one, but not the other construction, and how the structural differences could be accounted for. In the following, I will go briefly through these, taken from Grohmann $(2000 a, b)$, which, in turn, expand on earlier observations from the works cited above.

\subsection{Connectedness effects}

I address connectedness issues first. I take the Case-matching property of CLD to be the starting point for an account of how and why CLD and HTLD differ (taking up ideas from van Riemsdijk \& Zwarts 1974, Vat 1981, van Haaften et al. 1983). If only one construction forces the left-dislocated element and the resumptive to agree in Case, could it be possible that the dislocated element actually originates somewhere lower and undergoes movement to the left periphery, while the hanging topic is base-generated in its surface position? If this were the case, we would expect that at the relevant level of interpretation, LF, the left-dislocated element in CLD would be able to license relations that could not be licensed in case it is base-generated in the left periphery. Binding relations are a good case in hand.

If the left-dislocated element had indeed moved from a position lower in the clause in CLD, but not HTLD, we would expect differences with respect to reconstruction. The three cases I illustrate this with briefly are Weak Crossover, Principle A, and Principle C effects. ${ }^{3}$

3 Underlining marks the desired binding relations. The ungrammaticality judgements in this section are not necessarily absolute but refer to the intended interpretation. 
a. Seinen Vater, den mag jeder.

his-ACC father RP likes everyone.

'His father, everyone likes.'

b. Freunden von einander, denen erzählen $\underline{\text { Herforder }}$ selten

Lügen.

friends-DAT of each.other RP tell Herfordians rarely lies 'Friends of each other, Herfordians rarely tell lies.'
c. * Der Tatsache, daß $\underline{\text { Peter }}$ kein Geld hat,der mißt er the-DAT fact that Peter no money has RP measures he keine Bedeutung bei. no meaning PRT
'*The fact that Peter has no money, he doesn't attach any significance to.'

In each of the constructions in (3), the left-dislocated element and the high $d$-pronoun match in Case. In (3a), we can witness a Weak Crossover violation (see Postal 1971, Wasow 1972, Koopman \& Sportiche 1982, and much work since): the subject-quantifier is not expected to bind the pronominal element inside the left-dislocated phrase unless it ccommands it at some point of the derivation; indeed, (3a) is fully grammatical, even under the bound variable reading. The intended meaning in (3b) is also available; the anaphor inside the left-dislocated phrase can take the subject lower down in the structure as its antecedent; again, this is not expected under Principle A of the Binding Theory (or its minimalist equivalent) unless it has moved from lower down. In ( $3 \mathrm{c})$, we can witness the opposite effect: a referential expression inside the left-dislocated phrase cannot be coreferent with a lower pronoun; if the phrase were base-generated in the left-peripheral position, this would be unexpected and, in turn, if it had moved from lower down, this is exactly what we would expect.

The following sentences basically form minimal pairs: $(4 \mathrm{a}-\mathrm{c})$ are the equivalent HTLD instances of (3), where the resumptive is a $d$-pronoun in high position, while $\left(4 \mathrm{a}^{\prime}-\mathrm{c}^{\prime}\right)$ exhibit a $p$-pronoun as resumptive in low position. The grammaticality judgements are reversed this time. The same effect can be witnessed in the English translations: while CLD seems to be best expressed as a topic construction, HTLD mirrors English left dislocation.

(4) a. * Sein Vater, den mag jeder.

$a^{\prime}, *$ Sein Vater, jeder mag ihn.

'*His father, everyone likes him.'

b. * Freunde von einander, denen erzählen Herforder selten Lügen.

b'. * Freunde von einander, Herforder erzählen ihnen selten Lügen.

'*Friends of each other, Herfordians rarely tell them lies.'

c. Die Tatsache, daß $\underline{\text { Peter }}$ kein Geld hat, der mißt er keine Bedeutung bei.

c'. Die Tatsache, daß peter kein Geld hat, er mißt ihr keine Bedeutung bei.

'The fact that Peter has no money, he doesn't attach any significance to it.'

In other words, the three phenomena illustrated in (3) suggest that the left-dislocated phrase can reconstruct at LF to a lower position, low enough to allow the intended binding relations to take place $(3 \mathrm{a}, \mathrm{b})$ or rule them out (3c); see also Fox (1999) on reconstruction. Given the contrast with the variations in (4), it can only be the left-dislocated element itself, especially as $(4 \mathrm{a}-\mathrm{c})$ contain the same structure and the same resumptive in 
the same position. This is the first piece of evidence that the left-dislocated element originates inside the clause.

\subsection{More evidence for derivational and structural differences}

But there are more reasons to believe this. In fact, the observations made here strongly suggest that the left-dislocated element in CLD originates in the same position in which the resumptive of HTLD originates, regardless of whether that ends up in high or low position, or whether it is a $d$ - or a $p$-pronoun. They further suggest that the hanging topic is base-generated in its surface position. If this is so, the question arises how the resumptive gets where it is in CLD constructions. This question will be addressed in section 2.4 in terms of „copy spell out," and some consequences of the analysis will be explored within a framework outlined in the remainder of this paper.

Consider the following minimal pairs in (5) for CLD and (6) for HTLD:

a. *Seinen Vater, den haßt Berta die Tatsache, daß jeder mag. his-ACC father RP hates Berta the fact that every likes

'*His father, Berta hates the fact that everyone likes.'

b. Den Kopf, den hat Aaron der Berta gestern verdeht. the-ACC head RP has Aaron the Berta yesterday turned

'Berta's head, Aaron turned yesterday.'

c. Carlglaubt, den Aaron, den mag die Berta. Carlbelieves the-ACC Aaron RP likes the Berta 'Carl believes, Aaron, Berta likes.'

(6) a. \#Sein Vater, Berta haßt die Tatsache, daß den jeder mag.

a'. \#Sein Vater, Berta haßt die Tatsache, daß jeder ihn mag. '\#His father, Berta hates the fact that everyone likes him.'

b. *Der Kopf, den hat Aaron der Berta gestern verdeht.

b'. *Der Kopf, Aaron hat ihn der Berta gestern verdeht.

'*Berta's head, Aaron turned it yesterday.'

c. *Carl glaubt, der Aaron, den mag die Berta.

c'. *Carl glaubt, der Aaron, die Berta mag ihn.

'*Carl believes, Aaron, Berta likes him.'

The a-examples contain an island (here, a complex noun phrase) across which the resumption relation between left-dislocated element and pronominal is intended to hold. Ross (1967) provided good reasons to assume that movement out of islands is not possible, a generalization that certainly holds for strong islands as employed here. In (5a), both are outside the island, but at least one element must be interpreted inside. If either one had moved, we would expect an island violation, and in fact the sentence is ungrammatical. In (6a), the resumptive is in a high position inside the island, in (6a') it is low. Neither construction is ungrammatical, as ( 5 a) is, but neither can allow a bound variable reading. That is to say, the interpretation of both sentences involves one specific father. Note that if the resumptive were outside the island in (6a), the construction would be ungrammatical; furthermore, if Case-matching were to take place in (6a), thus creating a possible CLD (which, in case it has not yet been noted, may look ambiguous with HTLD), the bound reading is also not available. 
In the b-examples, an idiomatic chunk is left-dislocated. According to Marantz (1984) and others, any displacement of idiomatic material indicates movement, not basegeneration of the element in question, as the construction receives its idiomatic interpretation only in one relevant configuration. There are idiomatic expressions, such as the one used here which allow displacement of idiomatic chunks (at least in German). As the contrasts show, this applies only to CLD, not HTLD, suggesting that the left-dislocated element in CLD moves.

The c-examples, lastly, show that CLD may be embedded, while HTLD may not. As all cases of left dislocation in German require a verb second context, the only way to test embedding possibilities is to put them in the context of a so-called „bridge verb“ which allows for a verb second complement clause. While the contrast between $(5 \mathrm{c})$ and $\left(6 \mathrm{c}, \mathrm{c}^{\prime}\right)$ does not really tell us what moves where, if anything, it tells us something about the difference in structure. We seem to be dealing with a root phenomenon (in the sense of Emonds 1970) in one case but not the other. The c-examples suggest that the leftdislocated constituent in CLD sits in a different position than in HTLD; moreover, given the evidence, we could say that it moves to a position different from where the hanging topic is base-generated.

\subsection{An analysis for German left dislocation}

I propose that the left-dislocated element in CLD is originally merged into the same position into which the resumptive is merged in HTLD. (In the case of argument-DP left dislocation, this would be the thematic position; other cases are considered in Grohmann 1997, 2000b). In HTLD, and also English left dislocation (which thus is a type of HTLD), the resumptive undergoes all necessary movements: overt Case-movement in German, covert in English, yielding the construction in which the resumptive is in low position, and optionally topicalization, where it moves into high position. The hanging topic itself is base-generated as an adjunct of CP. In CLD, on the other hand, the leftdislocated element undergoes overt topicalization and then moves to the specifier of CP. The resumptive is introduced derivationally, as the Spell Out of the topic copy of the leftdislocated element. This automatically gives us the Case-matching property of CLD, while it also allows for the possibility of reconstruction only in CLD, as well as accounts for the other (non)movement diagnostics we observed.

We can capture the different derivations for left dislocation of a direct object as in the following abstract representation (cf. (2)), irrelevant steps excluded:

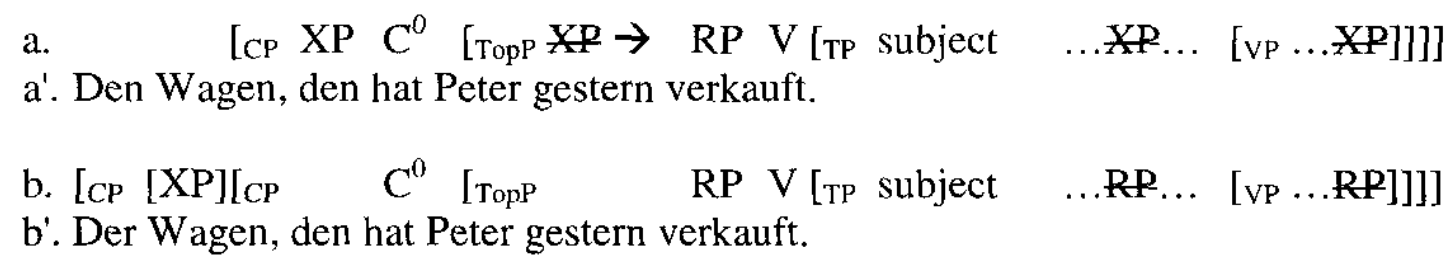

$$
\begin{aligned}
& \text { c. }\left[\mathrm{CP}[\mathrm{XP}]\left[\mathrm{CP} \quad \mathrm{C}^{0} \quad\left[\begin{array}{llll}
\mathrm{TP} & \text { subject } \mathrm{V} & \ldots \mathrm{RP}
\end{array}\right][\mathrm{vP} \ldots \mathrm{RP}]\right]\right] \\
& \mathrm{c}^{\prime} \text {. Der Wagen, Peter hat ihn gestern verkauft. }
\end{aligned}
$$

This is a good place to divert for a moment. Let me clarify two properties about phrase structure that play an important role in the version of minimalism adopted here. All movement is driven by the need to check formal features, for morphological reasons (Chomsky 1995). Features are checked in specifier-head configurations. In other words, all moved phrases must target a specifier position. I assume that nothing in principle rules out adjunction (to maximal phrases), which in turn suggests that adjoined elements must be licensed in a different way from feature-checking. (Note that both assumptions 
are needed independently under standard conceptions of successive-cyclic head movement: complex heads are the result of head-adjunction, and the type of checking does not take place in a specifier-head relation.) Without further discussion, let us assume that this licensing falls out from semantic properties of adjunct and adjunctee. Firstly, thus, all movement targets specifiers and adjoined positions cannot be the result of movement; secondly, multiple adjunction is legitimate. ${ }^{4}$

We can illustrate these properties of $X^{\prime}$-structure and movement as in (8), where a dashed line indicates an adjunct (AdjXP) and a full line a specifier (SpecXP):

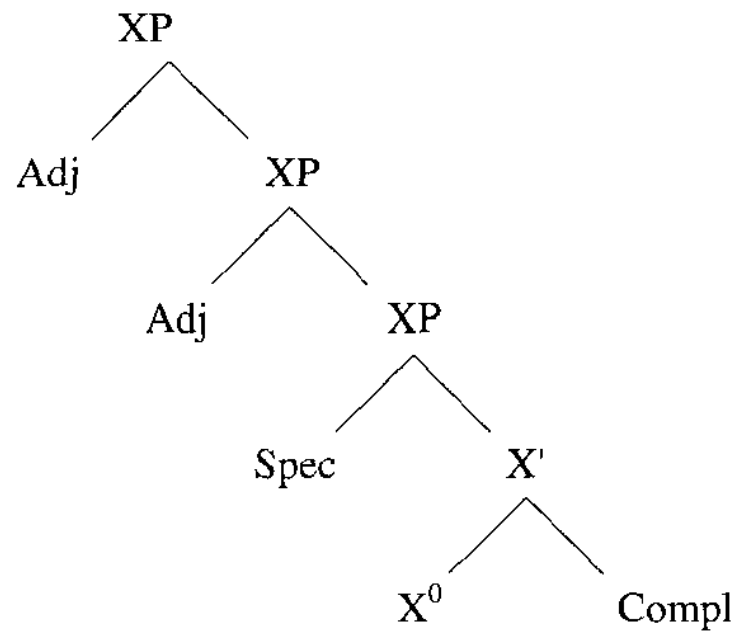

Returning to left dislocation, we can immediately see the benefits of a distinction between specifier and adjunct: it gives us the desired structural difference between hanging topic and the left-dislocated phrase in CLD, while it, at the same time, expresses their close relation. The former benefit would at least account for the different behaviour in embedding, while the latter captures the apparent similarities in form and function between the two.

Roughly speaking, left dislocation is topicalization plus ,a little extra,“ so to speak (see Gundel 1974, Birner \& Ward 1998 or Prince 1998, among others, for discussion of pragmatic similarities and differences between the two which I cannot treat here). It thus seems desirable to correlate the two up to a certain point. Under the current analysis, we can express the similarity with the role of the topic position; the „extra step" can also expressed: topicalization and CLD are both derived by a derivational process (movement), where CLD entails topicalization and subsequent movement of the same element. Given that CLD and HTLD are functionally very similar, it makes sense conceptually to evoke only one position for left-dislocated elements, CP. Moreover, if only one moves (and checks a relevant formal feature), we would like to express the difference between

4 Multiple specifiers have become considerably fashionable in recent years (e.g., Ura 1994, 1996, Chomsky 1995, Richards 1997). This is no place to argue against this concept in any detail, so I have to refer the interested reader to Zwart (2000) who argues convincingly against multiple specifjers of $v \mathrm{P}$ on mainly empirical grounds, Zwart (1997b) who presents good empirical and conceptual evidence against multiple specifiers of TP, or Hornstein (in press) who lays out shortcomings of multiple specifiers of $\mathrm{CP}$, for instance.

Note that the option of multiple specifiers hinges on two assumptions: features are crucially distinguished between interpretable and non-interpretable ones, and heads may optionally bear one (or more) additional uninterpretable feature(s) allowing for additional specifiers, as per Chomsky (1995:352ff.) which has become something of a minimalist standard (Chomsky 1998b, 1999, and much related work). In general, this approach has very little to say regarding actual orderings of constituents purported to be related to one head. 
moved and base-generated elements, and the above assumptions are able to do exactly that.

So far, we deal with a stipulation that allows us to express the differences between CLD and HTLD. There is, however, empirical support for the assumption that specifiers and adjuncts are different, and considering (7) and (8), we can make two predictions which can be captured neatly under the assumptions just laid out. If specifiers are unique and adjuncts are not, and if adjuncts are base-generated, we would expect - under the analysis of left dislocation schematized in (7) - that the moved left-dislocated element in CLD is unique, while the base-generated hanging topic is not. Moreover, we would expect both to co-occur, and, given (8), predict that any hanging topic must precede the leftdislocated element in CLD.

All these predictions are borne out. Although more than one left-dislocated element in a sentence takes away some of its naturalness, there is a clear contrast between the constructions in (9) and (10), where the single moved left-dislocated phrase is boldfaced:

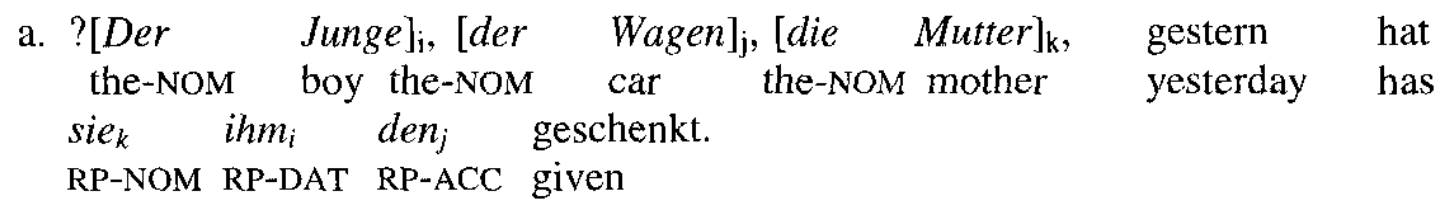
'The boy, the mother, the car, yesterday she gave it to him.'

b. ?[Der Junge $]_{\mathrm{i}}[\text { die Mutter }]_{\mathrm{k}}[\text { den Wagen }]_{\mathrm{j}}$ den $_{j}$ hat sie $_{k}$ ihm $_{i}$ gestern geschenkt. 'The boy, the mother, the car, yesterday she gave to him.'

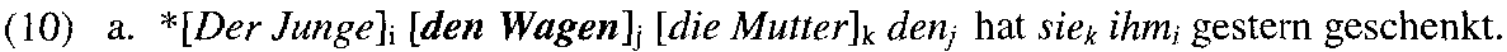

b. * ${ }^{*}$ Dem Jungen $]_{\mathrm{i}}[\text { der Wagen }]_{\mathrm{j}}[\text { die Mutter }]_{\mathrm{k}}$ dem $_{i}$ hat sie $_{k} i{ } n_{j}$ gestern geschenkt.

We can imagine more possible combinations of the relevant elements for (10), but they all lead to equal ungrammaticality, in stark contrast to (9), where multiple hanging topics are possible, obligatorily preceding the moved left-dislocated element.

Likewise, we can show that the moved element is indeed unique:

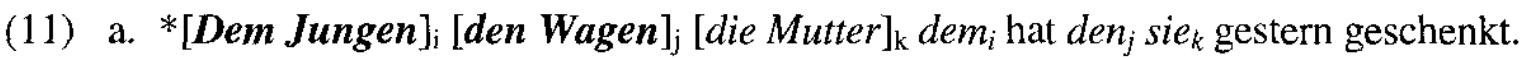
b. ${ }^{*}[\text { Die Mutter }]_{\mathrm{k}}[\text { dem Jungen }]_{\mathrm{i}}[\text { den Wagen }]_{\mathrm{j}}$ dem $_{i}$ hat $d e n_{j}$ sie $_{k}$ gestern geschenkt.

Again, while a number of possible analyses for the contrasts between CLD and HTLD come to mind, the most natural is the one which makes the best predictions, in addition to conceptual and empirical appeal. The present analysis of left dislocation, coupled with a possibly independently desired articulation of specifiers and adjuncts, can deal with a variety of predictions and captures the empirical facts, shown for convenience in (12) for (9b), where the resumptive element den is the spelled out form of the copy of den Wagen 'the car' which, in turn, has moved from lower down in the structure (ultimately, the complement position of the verb):

(12) [cP der Junge [cP die Mutter [ $\mathrm{CP}$ den Wagen $\mathrm{C}^{0}$ [TopP den hat-Top ${ }^{0}[\mathrm{TP}$ sie ihm ... $\left.\left.\left.\left.]\right]\right]\right]\right]$

But is this analysis really conceptually appealing? It makes one crucial assumption: an element may spell out its copy with a different PF-matrix. Under the Copy Theory of movement (Chomsky 1995, Nunes 1995), displacement is the result of copying and remerging an element. Presumably for PF reasons (such as linearization; Nunes 1999), any copy left behind must be (phonologically) deleted; it remains there for interpretive proc- 
esses (such as reconstruction). If we said that the resumptive is a spelled out copy, we would have to address this issue, and I do so in section 4. More importantly, however, we will have to ask ourselves what should motivate copy-spell outs, and whether we find spelled out copies in cases other than CLD. A possible answer for both will also be provided in section 4 .

The answer I suggest to the question of how and why copies may be spelled out is that otherwise the attempted move would be illicit. Specifically, I propose that the resumptive in CLD can, actually must, be spelled out because it rescues a movement which is ruled out, namely movement of one element from one position to another within the same domain. Recall that the derivational history argued for here involves movement to TopP and subsequent movement to CP in the case of CLD. Arguably, both projections are part of what used to be simply CP or COMP. Over the past decade, arguments have accumulated that this part of the clause structure should be more differentiated (see, among others, Cardinaletti \& Roberts 1991, Müller \& Sternefeld 1993, Rizzi 1997), influenced by similar work on INFL (Pollock 1989 and much subsequent work). The projections proposed for a split $\mathrm{CP}$ include positions for topic, focus, Wh-elements, typing particles etc. In other words, we can find a common cover term unifying the function of what we may call the C-domain: discoursal properties.

If a split CP may be subsumed under the cover term "discoursal properties“ and lead to an interesting approach to grammar, we might wonder whether other parts of clause structure could also be similarly identified. In the following I lay out a framework that splits clause structure into three prolific domains: the $\mathrm{V}$-, the $\mathrm{T}$ - and the $\mathrm{C}$-domain. I attempt to show that maximal phrases tend to occur only once in each domain, a sort of „XP-uniqueness.“ This tendency is maybe not as obvious as it is intuitive, but $\mathrm{I}$ have to refer the reader to chapter 1 of Grohmann (2000c) for detailed discussion of apparent counterexamples. Nevertheless, the idea behind the tripartition should become clear, and I assume that despite some details left out, it may provide us with an interesting way of thinking about dynamic derivations.

\section{Reflections on phrase structure and the composition of clauses}

Before motivating the explanation for spelling out certain copies, in the case of CLD and elsewhere, I present an idea on clause structure that aims at showing how maximal phrases tend to occur only once within each of the clausal areas ultimately dominated by $\nu \mathrm{P}, \mathrm{TP}$ and $\mathrm{CP}$, given more or less standard assumptions regarding their finer individual structures.

\subsection{Concerning the V-domain}

Let us start with the lowest part, the proclaimed V-domain. This domain can be unified in the sense that it licenses thematic properties. Uniqueness of XPs in this part of clausal structure can be shown relatively easily; I therefore restrict myself to one type of example.

One unambiguous case of XP-uniqueness in the V-domain comes from reflexivization, a phenomenon I will come back to below. Especially when we consider an analysis that links reflexives and their antecedents derivationally, as recently proposed by Hornstein (in press), the question arises why we could not merge an argument and move it around to achieve reflexive interpretation and then delete the lower copy as in other cases of movement.

To focus on English, we do not say (13a) to express (13b), relevant parts boldfaced: 
(13) a. * John likes.

b. John likes himself.

Neither can we employ (14a) to mean (14b):

(14) a. * John introduces Mary (to).

b. John introduces Mary to himself.

On the same token, (15a) does not mean (15b), but is ungrammatical, just as the other aexamples above; the same applies to (16), where the intended anaphor is a reciprocal.

(15) a. * John presents Mary (to).

b. John presents Mary (to) herself.

(16) a. * John puts the cards (on).

b. John puts the cards on each other.

In other words, movement of arguments within $v \mathrm{P}$ as schematized in (17) is ruled out, given that the internal structure of the $\mathrm{V}$-domain $(\nu \mathrm{P})$ looks something like this (where AGent, THeme and GOal are simply conventions). ${ }^{5}$

a. *

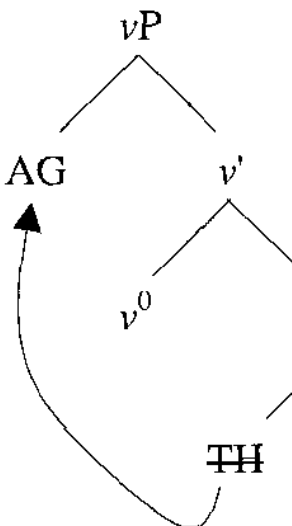

b. *<smiles>[Y17]1CCCCC1</smiles>

c. *<smiles>CP=C(C)C</smiles>

$\mathrm{AG}$
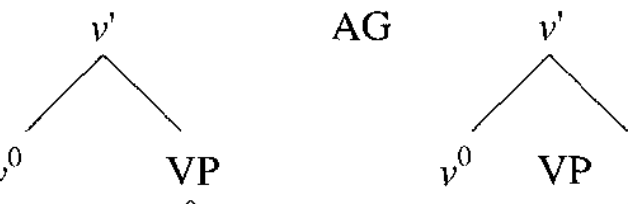

$\mathrm{AG}$
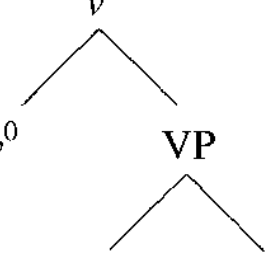

$\mathrm{TH}$
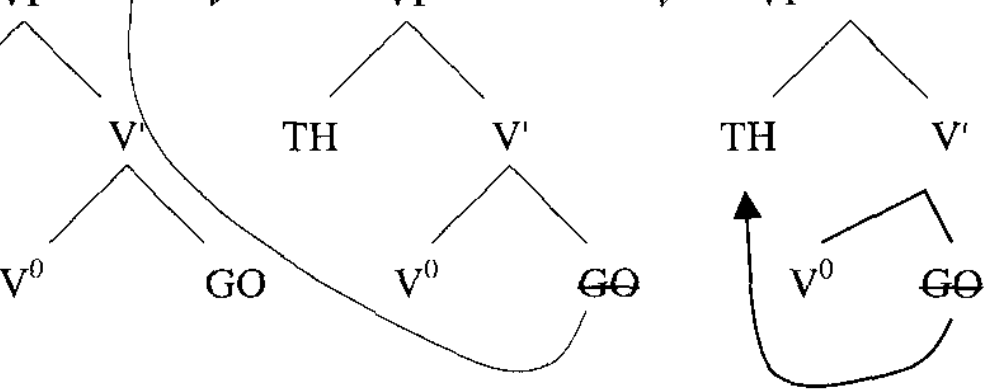

In (17a), corresponding to (13a), movement from theme to agent position is ruled out; likewise, movement from goal to agent position is forbidden, as in (17b), corresponding to (14a), and from goal to theme position (as in (17c), corresponding to (15a) and (16a)).

It seems as if XP-movement within $v / \mathrm{VP}$ is not allowed. ${ }^{6}$ Another issue relating to the structure of $\nu \mathrm{P}$ concerns adverbs. Certain adverbial modifiers are traditionally assumed to

5 The exact structure of $\nu \mathrm{P}$ is irrelevant for what follows and the main point made, namely that $\nu \mathrm{P}-$ internal arguments are restricted to one occurrence in this part of the structure. It does not matter here whether direct and indirect object (or 'theme' and 'goal') are generated in the order illustrated in (6) or some other way.

Important works on the structure of v/VP include Larson (1988), Dowty (1991), Hale \& Keyser (1993), Marantz (1993), Koizumi (1994), Anagnostopoulou (1999), among many others. For simplicity's sake, I refer to the three argument positions in this part as 'agent', 'theme' and 'goal', without subscribing to a particular approach. As might become clear, I endorse an approach that rids the grammar of its last deep structural remnants such as the Theta Criterion, as argued by Hornstein $(1998,1999$, in press). Under this approach, thematic properties are nothing but formal features which need to be checked off just as any other such features. If the present approach is on the right track, we can dispense with the Theta Criterion, and related configurational principles, independently. 
be $v$ /VP-related, not only semantically, but also structurally. Jackendoff (1972), for example, adjoins manner adverbs to VP, and this has been the standard way of integrating adverbs ever since (see e.g., Ernst 1984, forthcoming). Recent work by Alexiadou (1997) or Cinque (1999), on the other hand, seeks to dispense with adjoined positions altogether, much in the spirit of Kayne's (1994) antisymmetry approach to syntax, and argues that all adverbs are specifiers of separate projections.

As seen above, it is not unreasonable to assume not only that adjuncts in the classical sense exist, but also that they are different from specifiers at least in number (cf. (8) above). Thus, to the extent that certain adverbs are licensed in the V-domain, they must be adjoined to either VP or $v \mathrm{P}$, and they may not move from one to the other position (see also below).

In sum, $v$ P-internal XPs have one 'slot' only, regardless of our understanding of 'theta roles' (for example, configurationally as in Hale \& Keyser 1993, as proto-roles per Dowty 1991 or qua formal features à la Boskovic 1994 and many others; see also note 5). One might, of course, be tempted to account for the effect of this condition by some form of the Theta Criterion (Chomsky 1981) which postulates a biunique relationship between theta roles and arguments, but we will see presently what other problems that runs into. Apart from the Theta Criterion, it is not immediately obvious to me how one would rule out the illicit movements in (17) on principled grounds. One goal of the proposal presented here is to derive (17) and analogous structures in the other parts, or prolific domains, as well.

\subsection{Concerning the T-domain}

Next, I briefly investigate whether we can find evidence that the same reasoning can be applied to the subsequent area in clausal structure, the functional layer ultimately dominated by TP. We can call this the T-domain which is characterized by licensing grammatical properties - and here I do not refer to the grammatical function of an element, but rather its formal features pertaining to Case- and $\phi$-features.

In the T-domain, the empirical realm is not as clear-cut as in the V-domain. For one, we have to deal with more projections and hence more possible positions for XPs: while the V-domain makes available three positions for up to three elements, the T-domain arguably has more than three possible (specifier) positions, even under a conservative estimate, and consequently many more possible movements to rule out. For this reason, I only sketch a possible line of reasoning for the T-domain; the jdea behind it should be clear, and concentrating on the left periphery, we should keep the discussion to a minimum, even though some of the more controversial cases can be found in this part of the clause.

Nevertheless, a similarly paradigmatic case can be constructed for the T-domain as for the V-domain, and in fact it has been evoked to partly motivate the Case Filter. Just as all arguments must receive one and only one theta-role, (at least) all noun phrases need to be Case-marked, and they can only be Case-marked once, i.e. receive one morphological Case. If Case-marking is the reflex of a spec-head relationship, and if all (at least, structural) Case is checked inside the T-domain, ${ }^{7}$ we could recourse to XP-uniqueness for the illicit structures in (18):

6 Contra Koizumi (1994) and follow-ups who assume a 'split VP-layer' in the sense that functional projections such as AgrP are contained within. Assuming that Case/agreement properties must be dissociated from thematic ones, not only functionally but also formally (Chomsky 1993, Haeberli 1995), any such attempts must be rejected on independent grounds; more reasons will be given in the remainder, where different properties are ascribed to entire domains (viz. the thematic V-domain vs. the grammatical T-domain).

7 Note that within Checking Theory, the traditional distinction between structural and inherent Case is not so easy to maintain anymore. Moreover, if people like Zwart (1991, 1993, 1997a) are on the right track, 

a. * Den Vater mag sein(en) Sohn. the-ACC father like his-NOM(ACC) son intended meaning: 'The father likes his son.'
b. * Der Vater gibt
sein Sohn das
Buch.
the-ACC father gives his-ACC son the-NOM/ACCbook intended meaning: 'The father gives his son the book.'

(18a) can be envisioned to follow a derivation where the object stays in its theta-position and the subject moves to check accusative Case first, and then moves on to the canonical subject position. In (18b), the indirect object would have checked accusative Case first before moving on to the Case-position of the direct object. In other words, we want to rule out that one expression may check two Case-features within one clause. Alternative derivations for (18) do not come to mind, especially not if multiple specifiers are banned.

We can further hypothesize, on the basis of (17), what kinds of movement within the T-domain should be illicit; hence, what we would be looking for are ill-formed structures of the sort illustrated in (20), given the hierarchy in (19) for the T-domain: ${ }^{8}$

$$
\text { AgrSP }>\text { TP }>\text { ModP }>\text { AgrOP }>\text { NegP }>\text { AspP }>\text { VoiceP }
$$

a. *

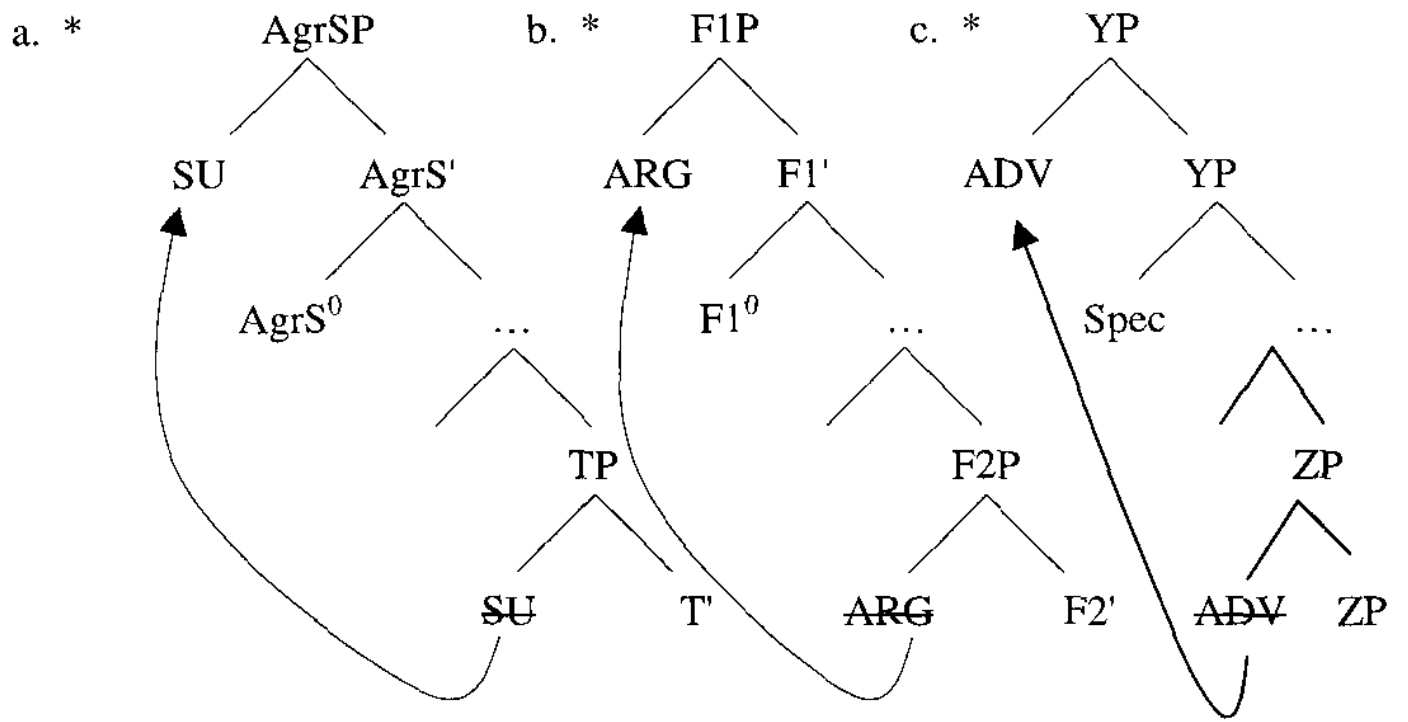

b. *<smiles>C[PH+]C</smiles>

c. *<smiles></smiles>

We could envision a split position for the SUbject, such as AgrSP and TP (as proposed by, e.g., Bobaljik \& Jonas 1996, Bobaljik \& Thráinsson 1998, but not as adopted here),

even some languages traditionally viewed SOV are underlyingly SVO (such as Dutch, German); this analysis forces overt movement of all argument DPs and could possibly be motivated by the need to check Case (nominative, accusative, dative etc.). However, if this is the driving force behind A(rgument)-movement in these cases, it should also apply to PPs, which also sit outside VP at Spell Out. Whether PPs can be argued to need Case (cf. Hornstein 1995) or whether some other feature need to be evoked is outside the scope of the paper. For simplicity's sake, let us assume that all DP and PP arguments must raise to some position in the T-domain to receive Case, either overtly as in German or covertly as in English (which is another story altogether).

8 I employ (19) for expository purposes, as most approaches to functional structure in this part of the clause deal with some version of this assembly. Extensive studies have been conducted since Pollock's (1989) seminal work and before. Independently, I assume TP to be the highest projection in this domain, the border between the $\mathrm{T}$ - and the C-layer. The standard argument is that $\mathrm{T}$ is the locus of the EPP, the first possible projection being able to license a minimally well-formed, finite clause. As the discussion below indicates, I dispense with Agr-projections altogether, but also with recent attempts to motivate multiple specifiers. Some details will be addressed presently; for the remainder of the paper, I have some version of the structure in (19) minus AgrSP and AgrOP in mind when I refer to the Tdomain. 
where different features are checked. ${ }^{9}$ However, if subjects may target either position, we would expect that if the position of a given XP in this part of the clausal structure is unique also, no subject should be allowed to move to both, as indicated in (20a). Likewise, no other ARGument should move to one functional projection F1P and then to another F2P within the area between CP and $v$ P, as shown in (20b). Moreover, ADVerbs, arguably maximal projections, are not expected to move from one position to another within the $\mathrm{T}$-domain, neither from adjoined to adjoined position (illustrated in (20c)), nor from a specifier to another (on a par with (20b)) - in other words, adverbs do not move at all (within any given prolific domain).

$(20 \mathrm{c})$ is immediately ruled out under the conditions on movement laid out above: if movement is driven by feature-checking and if feature-checking is the result of spec-head configurations only, movement to an adjoined position is ruled out. A number of approaches to grammatical phenomena in terms of adjunction via movement come to mind, and they all call for an alternative approach - to name but one, scrambling in German and Japanese has often been analysed as adjunction (to VP or IP). This view is not tenable anymore, not under the present set of assumptions, but technically, not under any minimalist theory that wants to derive all displacement on the basis of morphological needs. Many more cases can be constructed to illustrate that both (20b) and (20c) should be ruled out. All things being equal, this should thus also apply to the structure (20a), where transitive expletive constructions might pose a problem under either the minimalist version of Chomsky (1993) incorporating AgrSP and TP or Chomsky (1995) which employs multiple specifiers (see also note 9 ). ${ }^{10}$

As alluded to above, a unified account of XP-uniqueness of the sort witnessed so far is not readily available in current minimalist state of the art. While the uniqueness effects inside the V-domain we have seen above could plausibly be accounted for by the Theta Criterion, it is unlikely that something similar could take care of similar effects in the Tdomain - unless we want to evoke a (possibly large) number of unrelated conditions, such as the Case Filter to rule out certain instances of (20b) and semantic restrictions banning others, for example.

Moreover, it is not quite clear that we should want to stick to a (strict) manifestation of such principles in the first place: recent work argues convincingly against the Theta Criterion, which we will come back to presently; likewise, for a derivational system, any

9 The authors just mentioned, alongside others, argue not only for two subject positions (for certain languages), but also suggest that Case- and $\phi$-features be dissociated, i.e. checked in different positions. While I am sympathetic to the view that $\theta$ - and $\phi$-features should be licensed in different positions (Chomsky 1993, Haeberli 1995), I am not so sure that the same should apply here. Arising complications for the present view involve analyses of quantificational structures of Beghelli \& Stowell (1997), transitive expletive constructions of Chomsky (1995), Bobaljik \& Jonas (1996) and others, or French passives with participle agreement (as pointed out to me by Susi Wurmbrand). The obvious route to go here is to extend Chomsky's (1998a, 1999) notion of „Agree," possibly even further than Castillo et al. (1999) or Grohmann et al. (2000) do; one can thus imagine that rather than moving through intermediate positions, certain scopal relations could be the result of long-distance feature-checking in some instances. I have to leave out a discussion of these and ask the reader to suspend disbelief for the time being. (Alternatively, one could make the case that the rather T-domain itself consists of two domains, such as a quantificational one, as suggested by Anoop Mahajan, p.c.)

10 Transitive expletive constructions (such as witnessed in Icelandic or Dutch), and multiple subject constructions in general (Japanese, Korean, Chinese, Hebrew etc.), have been Ura's (1996) and Chomsky's (1995) main motivation to postulate multiple specifiers in the T-domain, specifically for SpecTP. I find the explanation there to be little convincing, as it does not only need additional assumptions on featurechecking to derive multiple specifiers (see note 4), it also needs to say something else that results in the correct ordering between expletive, subject, possibly adverbs, and verb (see Zwart 1997b for detailed criticism). Richards' (1997) condition that additional specifiers ,tuck in“ runs into independent difficulties both in cases of A-movement as weIl as $\mathrm{A}^{\prime}$-movement, which I cannot treat here (see Grohmann $2000 \mathrm{c}$, Hornstein, in press). 
stipulated filter or criterion based on structural representations is an unwelcome result. Furthermore, should we want to apply (some form of) „Fewest Steps" to account for derivational economy and locality (cf. Zwart 1997b), domain-internal movements are not welcome. While I leave open a finer analysis of problematic cases, I consider the idea of $\mathrm{XP}$-uniqueness in the T-domain agreeable, at least conceptually, which can potentially be justified empirically.

\subsection{Concerning the C-domain}

Extending the foregoing discussion, the obvious question to ask now is, of course: if we adopt a more articulated structure of COMP, do we find the same restrictions (seen above, at least in spirit)? In other words, given that the behaviour of XPs can possibly construed to involve only one occurrence per domain, can we make the case for this being so in the C-domain also?

Let us start with something like (21) as our structure of the C-layer, slightly modified from Rizzi (1997:297), and set the stage for the remainder (see Grohmann 2000c for more): ${ }^{11}$

$$
\text { CP }>\text { TopP* }>\text { FocP }>\text { TopP* }>\text { FP }
$$

On analogy with the illicit moves depicted in (17) and (20), (22) contains a sample of movements that would violate the uniqueness condition:

a. *

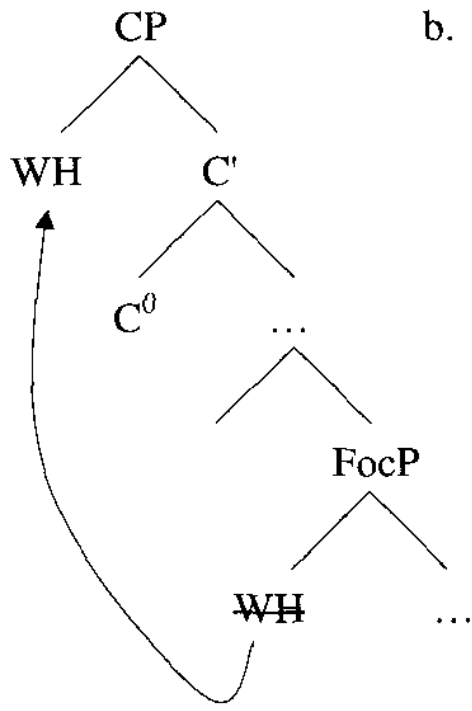

b. *<smiles>C[PbH](C)C</smiles>
TOPIC Top' c. * FocP

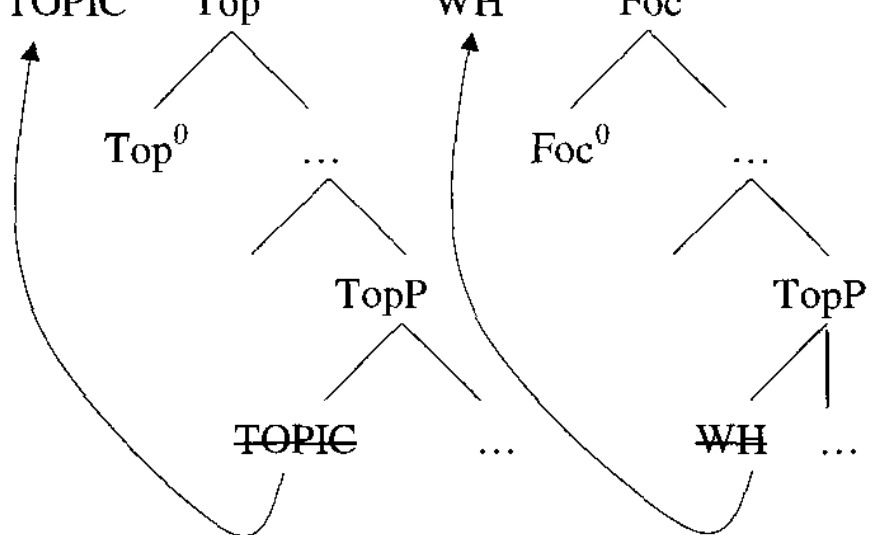

11 Without further discussion, I take Rizzi's ForceP to be CP, the ultimate landing site of complementizers and clause-typing elements. We will see below that certain instances of left dislocation are best understood as involving SpecCP (and AdjCP) - and in these instances, we can barely speak of ,illocutionary force" to be the trigger for movement (or licensing condition for adjunction). Here, I also do not follow Rizzi in assuming that finiteness must be anchored in the C-domain. This has also been argued for by Platzack (1998, in press) and others, following to some extent Enç (1991). If it turns out that Fin(iteness)P is needed after all, so be it; for the empirical coverage considered here, it plays no major role. I assume, however, FP, of fame from Uriagereka's (1995a,b) treatment of clitics in some Romance dialects and quasi-topic/focus constituents; see also Grohmann (in press) on the role of FP in West Germanic pronominal systems and Grohmann \& Etxepare (to appear) on its presence in root infinitival constructions across languages. And as hinted above, Top(ic)P should ideally be understood to be parameterized, whether it follows Foc(us)P or precedes it. An alternative, or additional path to follow, would be to identify two semantically distinct types of topic that occur in this domain. Again, the exact details shall not concern us here further. 
As with the T-domain, the empirical proof of the illegitimate moves within the C-domain shown in (22) does not come that easily as it does for the $\mathrm{V}$-domain, given that we have room for more variables. However, if there is anything to XP-uniqueness applying over certain parts of the clause, and if the domains constituted by the „,core functional heads" $\nu, \mathrm{T}$ and $\mathrm{C}$ (Chomsky 1999) behave alike in certain respects, the prediction is that the steps portrayed in (22a-c) should all be ill-formed.

Regarding (22a), the move from SpecFocP to SpecCP could possibly be envisioned under the following set of assumptions regarding Wh-questions: Wh-phrases, being inherently focused, target SpecFocP, if they move at all (i.e. not in Wh-in situ languages). CP serves as the locus of clause-typing (Cheng 1991) and could plausibly held to be responsible to host all Wh-elements at the relevant level of interpretation, i.e. LF.

However, these assumptions are not shared here. Rather, Wh-phrases indeed target FocP but need not, hence must not, move further; neither do non-moved Wh-phrases undergo LF-movement. Clause-typing is done in C, by movement of a Q-morpheme from some lower position (viz. Hagstrom 1998, and also Boskovic 1998, Grohmann 1999, Citko \& Grohmann 2000; see Boeckx 1999a for empirical arguments against Cheng's typology). It is [Q] that universally moves to $\mathrm{C}$, and Wh-phrases may (English) or may not (Chinese) move to FocP, or anywhere below (Serbo-Croatian). SpecCP is thus not a possible landing site. ${ }^{12}$

Hence, only (24b) is an admissible representation for the relevant part of (23):

(23) Who did Mary kiss?
a. * $[\mathrm{CP}$ who
$C^{0}[$ FocP wh...-$\left.]\right]$
b. $\quad[\mathrm{CP}$
$[\mathrm{Q}]-\mathrm{C}^{0} \quad[$ FocP who ... [Q] ... ]]

An instance of (22b) can be envisioned if we followed Rizzi (1997) to the dot and assume that FocP is couched in between two topic projections. Assume that (25a) and (25b) are both well-formed Italian sentences (Rizzi 1997:295-296), and that domani 'tomorrow' is a topic in both cases, with questo 'this' being the focused constituent:
a.
Credo
che a Gianni, QUESTO, domani,
gli dovremmo dire. believe.1SG that to Gianni this.FOC tomorrow him should.1PL say 'I believe that to Gianni, we should say THIS tomorrow.'
b. Credo che domani, a Gianni, QUESTO, gli dovremmo dire.

If XP-uniqueness can be shown to apply across the board and also to be a desirable empirical observation, domani must move to TopP in one step from wherever it originates, and not pass through a lower TopP inside the C-domain, as illustrated in (26): ${ }^{13}$

12 In fact, I argue that SpecCP serves a very limited function with respect to hosting possible elements; left dislocated phrases are one type that may appear here. Apart from that, this position is largely confined to being an escape hatch for extraction.

13 Independently of the notion „XP-uniqueness, “ if TopP may occur to both sides of FocP in one language, any element targeting the higher TopP should have moved through the lower one, given that locality on movement is subject to "Shortest Move," as is commonly assumed (cf. Chomsky 1995). This is not so if we adopt Zwart's (1997b) „Fewest Steps.“ In any case, from a semantic point of view, it does not make much sense to say that a language may split information structure into something like background - focus - background; it thus seems to be desirable to tease apart different notions of 'topic' and consider the elements to the left and to the right of the focused constituent in the Italian Cdomain illustrated in (25) to be intrinsically different, something that exceeds the focus of this paper by far. 
A technical implementation of XP-uniqueness would not only rule out (22c) in theory (for so-called 'Wh-topics'; see Wu 1996, Grohmann 1998), but also empirically. As the paradigm in (27) suggests, a Wh-phrase in English that possibly occupies a structural topic position - regardless of whether it moved to TopP first or last - is ruled out (adapted from Rizzi 1996:96; cf. Lasnik \& Saito 1992). ${ }^{14}$ Given that English Foc is verbal, at least in Wh-questions (cf. (27b)), and that Top is not (cf. (27a)), (27c) cannot feature the Wh-phrase in FocP; on the other hand, Wh-elements in English move to FocP overtly, so that we could not say that whom in $(27 \mathrm{c})$ sits in SpecTopP at Spell Out.

(27) a. Who believes that Mickey Mouse, the Americans will elect for president?

b. Who believes that whom will the Americans elect for president?

c. *Who believes that whom, the Americans will elect for president?

Naturally, the constructions presented here could also be ruled out by conditions other than XP-uniqueness. A number of operator criteria come to mind (such as the WhCriterion, Focus Criterion or Topic Criterion), and so do a number of semantic restrictions and conditions (such as the ill-formedness of an element to be focus and topic of a sentence at the same time). Again, however, we would have to enforce further, different principles on top of the Theta Criterion, Case Filter, and others.

\section{Tripartite clause structure}

In the following I lay out a rough formal partitioning of clausal tripartition, referring to these three areas as prolific domains, where the term ,prolific" alludes to the fact that each domain is made up of more articulate structure; I also address „XP-uniqueness“ in more detail.

\subsection{Prolific domains}

Capitalizing on the uniqueness observations for XPs across the clausal domain seen above, the core functional heads $v$, $\mathrm{T}$ and $\mathrm{C}$ could mark the boundaries for separate prolific domains:

(28) a. V-domain $(\theta \Delta)$ : part of the derivation where thematic relations are licensed

b. T-domain $(\phi \Delta)$ : part of the derivation where grammatical relations are licensed

c. C-domain $(\omega \Delta)$ : part of the derivation where discoursal relations are licensed

The layer responsible for selection requirements, call it ,thematic relations,“ encompasses the lexical verbal head $\mathrm{V}$, the functional verbal head $v$ and their respective complement and specifier positions; this part allows for up to three arguments, the internal

14 Notice that this seems to disarm my own previous analysis (Grohmann 1998), where it was argued that Wh-phrases in German all undergo movement to TopP ('topic' understood in a liberal sense to license "discourse-restricted quantification," the fact that even bare Wh-phrases seem to be discoursedependent), before the higher Wh-phrase then moves on to FocP (to type the clause). This blow in the face is only apparent, as that approach followed Cheng's (1991) analysis of clause-typing. By having the Q-morpheme do this part of information licensing, nothing forces ,double movement" of any Whphrase anymore, neither overtly nor covertly. A more refined analysis can be found in Grohmann 1999, $2000 \mathrm{c}$, and Citko \& Grohmann 2000. 
arguments (commonly understood as 'goal' and 'theme'; cf. note 5) and the external one ('agent'). Given that up to the point of completion of $\nu \mathrm{P}$ (by merging the external argument into SpecvP, glossing over possible adverbial modification or other adjuncts) - but not beyond - each XP is limited to one occurrence, this layer pertains to the thematic domain, or $\theta$-domain. (As a shorthand, I often refer to this part as the V-domain or simply $\theta \Delta$.)

Beyond $\nu \mathrm{P}$, a layer of functional projections emerges that licenses verbal morphology and agreement, from aspectual, negative and certain modal properties up to tense; TP, thus, is the projection that ultimately dominates the articulated INFL/S. The projections shown in (19) serve the main purpose to license verbal morphology (overtly or covertly). (See Baker 1988 on the Mirror Principle and cross-linguistic evidence for a hierarchy of verbal morphology.) This licensing is arguably achieved by checking through successivecyclic head movement. Moreover, the subject is licensed in SpecTP in spec-head configuration; dispensing with separate Agr-projections, all properties pertaining to Case-, agreement- and $\phi$-features would thus ideally be checked somewhere in this domain. Let us call the need of (argument) XPs to move into the T-domain grammatical or $\phi$ licensing, making this part the $\phi$-domain.

Running through further projections, and following the standard notion of successive head-movement, we reach the C-layer next. Initially conceived of as COMP or S', empirical evidence forces a more intricate technical analysis, such as the finer articulation of CP proposed by Rizzi (1997). I assume a structure such as (21), making available positions that express discoursal properties (such as point-of-view, topic, focus or illocutionary force). On analogy with the other two prolific domains, this part represents the $\omega$ - or C-domain.

So far, the concept of prolific domains presents a stipulation: clauses come in three layers with different properties over which a specific condition holds. But we can find possible support for this particular split in verbal morphology. Natural language possesses a myriad of verbal inflection through overt morphological marking, such as tense, aspect, voice or agreement of sorts (with subject, object or both) - all of which are construed with what I call the T-or $\phi$-domain; interestingly, though, there are no unique morphological markers defined over the $\theta$-domain (such as agent-, goal- or themeinflection) or the $\omega$-domain (such as Wh-, topic- or focus-inflection). ${ }^{15}$ In the following I aim at fleshing out this stipulation so as to make the concept of prolific domains to be real, well-motivated and derived. I further modify the concept of XP-uniqueness to capture dynamic derivations more adequately.

In sum, we can recreate (1) in slightly different form below, explicitly enough to capture the foregoing discussion and sketching out the framework I propose here:

(29) A prolific domain $\Pi \Delta$ is a part of the derivation (,dimension“) which identifies certain super-categories of information and provides the interfaces with it; each $\Pi \Delta$ consists of articulate internal structure, interweaving with derivational operations, namely at least:

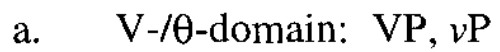
b. T-/ $\quad$-domain: VoiceP, AspP, NegP, ModP, TP
c. C-/ $\quad$-domain: FP, TopP, FocP, CP

15 Except, possibly mood; this concept is directly linked to other properties, however, which we can abstract away from for now. It does not really matter whether this state of affairs indeed holds. The reasoning is not meant to constitute an argument for anything, but can be simply viewed as another indication of the three-way split along the lines suggested here. 
The two levels of representation, PF and LF, are mapped cyclically: each time a prolific domain is established, it gets spelled out, i.e. shipped to the interfaces.

\subsection{Dynamic syntax}

Now that we have observed that a tripartition of clause structure into three domains seems at least plausible, we should ask ourselves what we are doing this for. If each of these prolific domains serves to license different properties, and if some form of XPuniqueness within a domain is real, what do prolific domains do then?

The intuitive answer I would like to give here is that a prolific domain $\Pi \Delta$ establishes local licensing of properties that, as different as they are, can be subsumed under a common header for each $\Pi \Delta$, roughly as sketched out in (29) and the preceding discussion. Moreover, we can build on the implicit relation between the (syntactic) derivation and the (interpretive) interfaces, much as implied by the diagram in (1) and the prose in (29) above. One of the major results of minimalist inquiries into natural languages, I take it, is the abandonment of superfluous levels of representation - regardless of whether the system is derivational or representational. Thus, what was believed to be indispensable components of syntactic structure, the levels of D- and S-structure, can safely be dispensed with under a different, reduced set of assumptions (such as Checking Theory, regardless of imperfections in design and implementation). The derived $\mathrm{T}$-model of the minimalist era links the lexicon (or a relevant subpart, the numeration) to the output (what we pronounce) through syntactic processes; basically, Merge, Copy, Move and Delete (see Chomsky 1995, Nunes 1995, Hornstein, in press). The indispensable levels of representation, LF (feeding the conceptual-intentional interface) and PF (feeding the articulatory-perceptual interface) are mapped from the derivation, after the point of Spell Out.

As has been argued recently, there is nothing in the minimalist framework that forces us to view LF and PF as levels of representation that are fed uniquely at one specific point. Remember, the standard conception is that the derivation unfolds, where Merge and Move apply (as well as Copy and Delete, presumably), up to the point of Spell Out. This is where the material gets pronounced, which may be affected by PF-movement. That is to say, at the point of Spell Out, the level of PF kicks in, allowing for further operations which have no effect on the interpretation. At that point, the structure is also sent to LF, where further operations apply to compute the semantic interpretation. If, as Aristotle remarked over two millennia ago, language is the pairing of sound and meaning, the split between the LF- and the PF-component is intuitive and desirable.

However, it is not so clear that they are both derived independently of the derivation. Uriagereka (1999), for example, suggests that the operation Spell Out, under standard conceptions a curiously unique operation, should be iterative just as other operations are. All instances of Merge and Move apply up to convergence, as needed; so why not assume that Spell Out also applies multiply, as needed?

One way to make this work is to designate specific points in the derivation that force spelling out - just as we have specific points in the derivation where we merge from the lexicon (numeration) or the derivation (workspace). For Uriagereka, every time a left branch is created, this sub-part is spelled out. Spelling out applies cyclically, just as other operations. The operation Spell Out freezes the phonological material of the relevant string. It ships its information to the interfaces (PF and LF). One advantage of spelling out left branches is an explanation for so-called "left-branch effects" found in many lan- 
guage (cf. Huang 1982). However, it is not so clear that all languages forbid such extraction. ${ }^{16}$

I take the idea of multiple Spell Out to be advantageous but relocate the point of Spell Out. Every time a $\Pi \Delta$ is established, relevant phonological and semantic information gets shipped to the interfaces. The levels of LF and PF are as dynamic as the derivation itself: they are fed successive-cyclically and hence force spelling out of partial derivations. There is a mapping from the derivation to the PF- and LF-interfaces as the derivation unfolds (cf. (1)).

As mentioned in note 16, Chomsky (1998a, 1999) also adopts some version of multiple Spell Out. In this extension, certain sub-parts of the derivation are relevant for the interfaces, which he calls 'phases'. The two functional heads $v$ and $\mathrm{C}$ induce a phase, much as they formed a barrier in earlier GB-frameworks (Chomsky 1986), but T does not. A phase spelled out bans any material from inside it to move out - unless it finds a local escape hatch, which basically boils down to moving to the edge of a phase and raise further. It is easy to see that this assumption crucially builds on the existence of multiple specifiers, which I, along with many others, find neither empirically nor theoretically well motivated (see discussion above and note 4). If multiple specifiers do not exist, moving to the ,edge of a phase" cannot mean much either. The idea, however, is as intuitive and welcome as Uriagereka's: as the derivation unfolds, conditions apply to subparts and need to be encoded. I thus take the concept of both multiple Spell Out and phases well-grounded and extend them here.

I see three possible points in the derivation which could be mapped to the interfaces:
a. spell out left branches
b. spell out phases
c. spell out prolific domains

(30a) arguably overgeneralizes, as Stepanov (2000) argues. (30b) cannot be derived, as the previous paragraph shows; strictly speaking, it might also be too weak, given recent criticism of limiting phases to $v$ and C (Uriagereka \& Martin 1999, for example, make the point that $\mathrm{T}$ should also induce a phase). This leaves us with $(30 \mathrm{c})$. Note that nowhere is it implied that all three possibilities are mutually exclusive, or to be more specific, the concept of 'phase' and 'prolific domain' may well go hand in hand. Nothing hinges on the uniqueness of either one. This shall be material for future endeavours, however.

If one consequence of a prolific domain is that its information is shipped to PF and LF (and the two levels of representation are thus dynamically derived), we can finally say something salient about „XP-uniqueness," that is why certain elements may not move within a $\Pi \Delta$. Given that each domain arches over separate pieces of information (roughly, thematic, grammatical and discoursal information, respectively) - although a multitude of features may be checked (such as different types of theta-features, Case- and

16 This presentation is, of course, a simplification of Uriagereka's framework. However, it is a fact that not all languages are as sensitive to left branches as English. Stepanov (2000) finds a systematic spit between SOV and SVO languages in that the former allow extraction out of subjects, whereas both groups disallow extraction out of adjuncts, which seems to be the real generalization. Stepanov accounts for the impossibility of extraction out of adjuncts by merging adjuncts post-cyclically (see also Stepanov 1999). This is not the time and place to criticize the empirical difficulty of his findings (which languages like Dutch or German pose), nor to investigate the theoretical basis of post-cyclic merging. In short, it is not clear that Uriagereka's desired effects can really be derived in an empirically adequate fashion without further assumption, nor is it obvious that Stepanov's proposal really fixes any shortcomings. Admittedly, the idea that only prolific domains are spelled out is even vaguer. Suffice it to say, questions arise and remain, but so they do other implementations of multiple Spell Out (such as spelling out phases as in Chomsky 1998a, 1999). 
agreement-features, topic- and focus-features etc.) - we can conceive of XP-uniqueness as the requirement that a given element may only bear the relevant specifications, or provide an ,address," for one domain.

However, we have already seen an apparent exception to this condition, namely the case of spelling out the topic copy in CLD. In the next section, we will see that this is not a unique occurrence of spelling out copies, and that we need to further modify XPuniqueness.

\subsection{Domains, dynamics and derivations}

Thus far, I have suggested that clausal structure, beyond its intricacies of functional projections and feature-checking, can be divided into three parts, or prolific domains. It should be obvious that this is simply an attempt to capture old ideas - there is nothing new or revolutionary about the concept of a tripartite structure. However, I try to go beyond and derive some interesting observations, namely that XPs are unique within a given domain. In this section, we will see some exceptions and implement these to redefine this condition, which in the ideal case would be derived rather than stipulated. Further on along the road, there is the claim that interpretation is derivational also, mapped successive-cyclically as the syntactic derivation unfolds. This might have strong consequences for future endeavours of the syntax-discourse interface, a larger issue of possible interest that I can only touch on tangentially. ${ }^{17}$

Things need not work this way. Platzack (in press), for example, also argues for a tripartition of clause structure, interestingly along the same lines pursued here. ${ }^{18}$ The framework he develops differs from the present one in one important aspect, however. While the model laid out here is dynamic and derivational, Platzack's is representational. Again, it is not quite clear how much longer this split among generativist syntacticians should be continued, but conceptually, there is one major difference between our two frameworks: Platzack treats each spelling out of a domain (though he does not use these terms) as establishing a separate level of LF-representation, while my derivation reaches a single LF through cyclical feeding of spelled-out material. Thus, he maps the syntactic derivation (or representation) of the clause not only to three domains - which he also takes to be „levels" in the formal sense - but also each domain to a separate LF, while mapping the three domains, in turn, to a single PF-level. More needs to be said regarding the difference of levels vs. components of representation (see e.g., Uriagereka 1999, Uriagereka \& Martin 1999), but for the time being we can take the advantage of the present framework over this representational alternative in holding fast to two levels of representation which yield the desired pairing of sound and meaning.

To come back to derivations and the status of XP-uniqueness, let us consider one further case where it seems to be violated, in addition to CLD. This time, the violation takes place in what we can now characterize as the V-domain. If there is anything to the idea behind unique addresses of maximal phrases for interface reasons, we would have good reason to assimilate both cases of copy-spell outs and modify XP-uniqueness in a possibly unified way.

17 The idea of feeding the interpretive components from the syntax is not necessarily shared by all researchers. Boeckx (1999b), for example, argues for opportunistic interfaces where the syntax does not feed the interfaces, but the interfaces feed on the syntax and take what they need for interpretation.

18 Christer Platzack and I have developed our frameworks completely independent of each other. What is striking, then, is that not only do we pursue the three-way cut, which is nothing new as already mentioned, but also assign the same properties to the three domains (in addition to calling the sub-parts „domains" of sorts). 
Hornstein (in press), reviving the original proposal by Lees \& Klima (1963), argues for a derivational account of reflexivization. The idea behind this is clear: given that antecedent and reflexive denote the same entity, and that there seem to be strict locality conditions, it should be possible to derive the identity between the two syntactically, not solely semantically (also Lidz \& Idsardi 1998). As we have seen in section 3.1, the derivational analysis cannot work on purely syntactic grounds - otherwise, John likes should be a well-formed structure allowing for the interpretation John likes himself which could be syntactically saturated (by copying the relevant features of John in theme position and remerging them into the agent position). Hornstein proposes a derivational procedure such as the following:

\section{(31) a. [v'likes John-self ] \\ b. [ [vP John likes [vp $t_{v}$ John-self ]] \\ c. [ [vP John likes [vP $t_{v}$ himself $\left.\left.]\right]\right]$}

John is indeed merged into theme position, but comes with the reflexive morpheme self which, as a bound morpheme, needs phonological material to be attached to. John then raises to agent position and spells out its trace, giving self a PF-matrix to be satisfied.

Syntactically, this part of the derivation is well-formed. John first checks its thetafeature 'theme', then its second theta-feature 'agent'. Hornstein builds on his earlier arguments that the Theta Criterion should not exist and that thematic properties constitute the same morphosyntactic reflex as any other formal features. ${ }^{19}$ Spelling out the copy is not only necessary for the reflexive morpheme to combine with, it is also driven by Caseneeds. Crucially, it is self that bears a Case-feature, and this needs to be checked. By copying the lower instance of John, all other features are transmitted to the higher copy. The result of spelling out is that himself can then undergo Case-movement.

Under our set of assumptions here, the movement from one position to another within the same prolific domain should be ruled out by „XP-uniqueness, " the very observation that led us to consider a formal tripartition in terms of prolific domains. The easy way out would be to reject the derivational analysis of reflexives. However, as we have seen in section 2 , something very similar seems to be going on in certain cases of left dislocation in German.

We could then capture both the framework laid out here and the derivational approach to reflexivization by understanding XP-uniqueness as follows. Movement of one XP within the same domain seems to be legitimate if it results in spelling out the copy. Note further that the spelled out copy looks different from the original, i.e. we do not say John likes John (similarly, we spell out the copy of the topic as a pronominal in CLD). In other words:

\section{Condition on Domain-Exclusivity ( $C D E)$}

No maximal phrase XP may have more than one address identification AI per prolific domain $\Pi \Delta$, unless it has a drastic effect on the output, i.e. the relevant copy of $\mathrm{XP}$ has a different form at PF - which is the result of spelling out the copy.

It is clear that it is the PF-matrix that is at stake, not the LF-features, given that the two copies are otherwise identical. This captures the Case Filter of GB-times, namely that only overtly realized material can check Case. I will thus assume the CDE to look as in

19 Relevant literature includes Boskovic (1994), Lasnik (1995, 1999), Boskovic \& Takahashi (1998), Hornstein (1998, 1999), Manzini \& Roussou (2000); see Hornstein (in press: chapter 5) for a more accurate discussion of the details of his approach to reflexivization. 
(32), and assume further that is falls out of the framework presented here and need not necessarily be a stipulated condition over derivations (or even representations).

The PF-relevance of spelling out copies also follows from Hornstein's account. As Juan Uriagereka (p.c.) points out to me, however, his analysis might be challenged by the following. Given that spelling out is forced for Case-reasons, we would expect that if the relevant position would not necessitate subsequent Case-checking, that element should be able to freely move to the higher position; all it would do is check an additional thetafeature.

\section{The fish ate.}

A relevant example is (33). The verb eat is usually a transitive predicate (cf. (34a)). The internal argument can, however, be left out, as in (33) which would be understood maximally as (34b), with the restriction that the eaten material be something that is generally considered to be edible and hence a possible candidate for default food by the eater. Given that some fish can eat other fish, and some fish even eat other fish of the same type, (33) should be possible to be interpreted as either (34c) or (34d). The former interpretation is possible, but the latter is not: the fish ate cannot mean that it ate itself (or they ate themselves).

(34) a. The fish ate algae.

b. The fish ate something or other.

c. The fish ate the fish.

d. The fish ate itself/themselves.

As Hornstein's approach solely considers properties and extensions of formal featurechecking mechanisms (theta- and Case-features in this case), with spelling out of copies being driven purely by the need to have overt material that can later on check Case, this state of affairs is not expected. The only way I can think of - suggested by Norbert Hornstein (p.c.) himself - is to assume that the two instances of eat in (33) vs. (34) are different. In one case, it is a regular transitive verb, and in the other it is a detransitivized verb. It is not clear that we want to go that route - if we do, fine. But if we want to maintain that there is only one lexical entry eat, with the caveat of optionally deleting a highly restricted type of internal argument, we would have to find a different solution.

Interestingly, we can adopt Hornstein's analysis pretty much as is, with the additional pay-off that this puzzle is taken care of. If spelling out of copies is not necessarily driven by further formal features only, to be checked at a later point in the derivation, but rather by a repair strategy to rule in an otherwise illegitimate move, the lack of interpretation of (33) in terms of (34d) falls out: an XP would move within a prolific domain without spelling out is copy with a different PF-matrix. I thus adopt the most important ingredients of Hornstein's analysis; ${ }^{20}$ coupled with the discussion so far and the analysis of CLD, this serves as empirical support to for the CDE in (32) and a unified account for spelling out copies. ${ }^{21}$

20 I leave open an adequate, cross-linguistic analysis of reflexivization, as it would drift us too far away. Naturally, not all languages work like English. Obvious differences can be found in Finnish and Kannada, for example. Both languages mark the verb with a special reflexivizer, and Kannada also employs a reflexive XP. One can make sense of these variations in terms of a domain-driven view of syntax by incorporation of the spelled out copy into the verb (Finnish) or of only a relevant feature in, with the spelled out copy itself remaining PF-visible (Kannada). Other possible solutions exist, none too far removed from the basic premises of this framework, but a wider range of languages would have to be subjected to investigation to go into more detail. I thank Jonathan Bobaljik, Jeff Lidz and Malte Zimmermann for discussion.

21 Note that technical details regarding economy of movement and locality conditions are left out. The picture painted so far strongly suggests to favour Fewest Steps (Zwart 1997b) over Move/Attract Clos- 


\section{Left-peripheral phenomena}

Lastly, I consider the left periphery again, looking at some cross-linguistic variation regarding the structure of the C-domain, especially syntactic instantiations of topic and focus.

\subsection{Topic constructions}

For English topicalization, as illustrated in (35), we need to assume a specific topic position, following the assumptions made throughout. If the subject typically sits in SpecTP at Spell Out and if TP marks the boundary from T- to C-domain, there are only two possible positions for topics: adjoined to TP or somewhere higher. However, given that argument topics are theta-marked in the $\mathrm{V}$-domain and Case-marked in the $\mathrm{T}$-domain, they have to derive from movement - and movement can only target specifier positions, with adjoined positions reserved solely for base-generated elements only. This has been argued for a number of languages already (e.g., Müller \& Sternefeld 1993, Rizzi 1997, and many others), and thus refutes the traditional analysis of Chomsky (1977) under which the topicalized constituent is adjoined to COMP, identified with its gap through movement of a null operator; the same should hold for fronted, arguably topicalized, adverbs for which a null operator-movement analysis sounds even less plausible. ${ }^{22}$ As a consequence, English topics are neither adjoined to TP, nor to some higher projection, but move to some specifier position above TP.

(35) a. Mary, John kissed./John kissed Mary.

b. His mother, everyone likes./Everyone likes his mother.

c. Carefully, the dog opened the food bag./The dog opened the food bag carefully.

I take the landing site for moved topics to be SpecTopP. Leaving aside a discussion of different types of 'topic' - where not all elements interpreted as topics have to be derived by movement - , TopP is a suitable candidate as it doubtlessly feeds the interpretive component directly. Given our discussion of prolific domains, in particular the $\mathrm{C}$ -

est (Chomsky 1995). Moreover, given a remarkable account of puzzles from GB-times, such as parasitic gaps or control into adjuncts, as explored by Hornstein (1998, in press), there are indications that Attract $F$ does not fare as well as Move F, the original concept of displacement in minimalism (Chomsky 1993). We can thus understand the need of an XP to move higher as the need to license its relevant feature-information (concerning thematic, grammatical and discoursal properties). Economy forces one step per domain, leaving aside the caveat of spelling out copies along the way. These issues are only tangential to our present interests.

As a side remark to the reader who might still be stunned by the absence of discussion of (transitive) expletive constructions; the standard raising analysis of the associate is not the only approach on the market (see Moro 1989, 1997, and others). In either case, the CDE is able to take care of such apparent violations, should it turn out that associate raising is correct: it simply is the reverse effect at LF, namely movement of an element to another, within the same domain, to establish interpretive identity. I will leave it at that for now.

22. Further discussion of adjoined elements needs to be postponed; see Stepanov $(1999,2000)$ for an idea that could do without movement of adjuncts. (Cinque (1999) does this too, but remember that for him, all adverbs are specifiers, an assumption not assumed here-and neither do I assume close to 40 projections in the T-domain to derive positions.) I can only think of either (optionally) higher adjunction, or movement from the base-generated site-which would then have to target a position in the Cdomain, and this position must be a specifier, taken all assumptions so far into consideration (which also can leave out non-cyclic adjunction). 
domain, it thus seems very plausible to locate TopP inside the topmost layer, the discoursal domain.

In German, under the view of prolific domains, dynamic derivations, and the syntaxdiscourse interface drafted here, we arguably deal with many instances of topicalization, in matrix as well as in embedded clauses. Holding fast to the assumption that subjects target SpecTP (unless further specified, be it through focus-, topic- or other features), and given that both TP is typically the highest projection of the T-domain and intra-domain movement is ruled out, the subject serves as a good indicator of domain-relation: roughly, every (moved) element preceding the subject must have raised into the $\mathrm{C}$ domain: ${ }^{23}$
a. [TopP Der Frau hat [TP Martin derfrat the-DAT woman has Martin
das Buch gegeben] the-ACC book given
'The woman, Martin gave the book to.'
b. [TopP Das Buch hat [TP der Martin der Frau das Buch gegeben]

The structural differences between these two prototypical (syntactic) topic-constructions in English and German allow for a first parameterization between the two languages: rather than saying that one language employs movement and the other base-generation of the topic, the English topic-head is not endowed with verbal features, while the German one is. In other words, the verb raises overtly to Top only in German (see also section 3.3).

While the rough structural representations in (36) are quite uncontroversial for German matrix clauses (cf. Müller \& Sternefeld 1993), the identification of material in presubject position as topic in embedded clauses is not (see Haider 1990 and many others). The current framework does not allow for any other option, a state of affairs I have independently argued for in previous work (cf. Grohmann 1996). Note that this account extends to cases of multiple fronting over the subject, also claimed to be topicalization in earlier work.

(37) a. ... daß [TopP der Frau [TP der Martin der Frat das Buch gegeben hat]

'... that the woman, Martin gave the book to.'

b. ... daß [TopP das Buch [тP der Martin der Frau Bas Buth gegeben hat]

'... that the book, Martin gave to the woman.'

(38) a. [Topp Der Frau hat [TopP das Buch [TP der Martin der Fegeben]

b. [TopP Das Buch hat [TopP der Frau [TP der Martin ter Fras Butegen]

Traditionally, the relevant parts of (37) and (38) are the result of „scrambling“ (Ross 1967; see Haider 1993, Müller \& Sternefeld 1993, Corver \& van Riemsdijk 1994, Müller 1995 , and references for some recent approaches). We now have fair support for the distinction between pre-subject scrambling and post-subject scrambling. The main problem with the phenomenon of "scrambling“ that should have emerged by now, of course, is the

23. For ease of exposition, I only illustrate with arguments. I take it that the issue of integrating adverbial modifiers is not yet solved, even within the framework of prolific domains (see also notes 16 and 22). More needs to be said regarding the linearization of left branches in general, both with respect to each other and with respect to heads. It is thus not clear whether the temporal adverb gestern 'yesterday' in (i) is adjoined to TP, as it should (roughly following the adverb literature), or derived some other way.

(i) a. Gestern hat Peter den Hund gefüttert. 'Yesterday, Peter fed the dog.'

b. Peter hat gestern den Hund gefüttert. 'Peter fed the dog yesterday.' 
difficulty of implementing the standard adjunction-analysis into any (minimalist) framework. By understanding pre-subject material to have raised into the $\mathrm{C}$-domain, we can circumvent at least part of the problem (see also Grabski \& Frey 2000 for interesting tests). While more than one element may move to TopP, locality constraints seem to exist which I cannot discuss here. ${ }^{24}$

This brief discussion illustrates one possible consequence of the framework sketched here. While arguably every sentence expresses discoursal notions (such as 'topic' or 'focus'), not every languages needs to do this syntactically. One major difference between a language that allows for word order variation like German, and one that does as not readily, such as English, is thus whether discourse-relevant properties have an impact on the syntax. While much of current syntactic thinking clings to the autonomy of syntax and denies pragmatic traits to enter syntax proper, one can scent some form of ,autocracy of syntax" where such notions are shoved off to other parts of the grammar altogether. What might look nice on paper has actually serious consequences for the empirical adequacy of the theory. It appears to me to be the case that by excluding such properties, the range of phenomena that can safely be accounted for shrinks to a bare minimum of (some) instances of A-movement and Wh-movement; it has been argued at one time or another that phenomena such as verb second (or second position phenomena in general), scrambling, object shift, and others best be excluded from formal syntax and explained away by „PF-effects,“ while notions such as a topic and focus might be relevant to semantics and pragmatics, but not syntax.

If we turn around our picture of the grammar and pursue some version of what I have suggested here, there is another way of thinking, one that does away with such a radical view without losing view of an independent syntactic component. What if languages differ in that some allow discoursal identification on surface structures only, while others allow feeding the syntactic component with this type of information? Then languages like German would make more use of the C-domain than languages like English, a tendency that is generally acknowledged and even further expressed in this article. Other empirical domains where an articulated inclusion of the C-domain could possibly make a difference are weak pronominal elements (as argued for by Grohmann, in press) and multiple Wh-questions (under the approach of Grohmann 1998, 1999, Citko \& Grohmann 2000).

A more salient discussion warrants for a formal mapping from syntax to discourse, extending models on information structure presently available (e.g., Vallduví 1992, Lambrecht 1994, Büring 1997, Erteschik-Shir 1998 and others). But we can easily envision an elaboration of the diagram in (1) that integrates the syntax-discourse interface even further, possibly parameterized (recapturing the old division of configurational vs. non-configurational languages from Hale 1983, for example).

\subsection{Focus constructions}

I finally want to consider some cross-linguistic data regarding focus constructions and basically show how structural focus positions are different from structural topic positions; moreover, this section serves to show that nothing should be odd about having multiple C-related projections, but rather that an articulated structure of the C-domain such as proposed by Rizzi (1997) and others may bear fruitful results.

24 It should be pointed out that I do not necessarily identify all pre-subject positions as topic positions; other factors might play a role also. What is crucial is that part of the analysis that (a) moves the fronted elements into specifier positions and (b) identifies the broad area of location as the C-domain, both falling out straightforwardly of the program sketched here so far. 
First, we can distinguish (at least) two instances of focalization (cf. É. Kiss 1998, Zubizaretta 1998, and ample references cited): (purely) prosodically marked focus on the one hand which is rather low in the clause structure, roughly corresponding to the default argument position, and syntactically marked focus which is derived by movement and presumably targets a high position. While the former strategy can be found in most, if not all, languages, the latter does not necessarily apply to all languages - and for many, it is simply an option. Thus, languages like Hungarian or Basque typically mark their focused constituents by some fronting operations, while English and German apparently tend to not do so.

In the latter, we can distinguish focus-in situ from non-focused in situ elements (where ,in situ“ refers to the default position at Spell Out, presumably in the T-domain, or Caseposition, for German and in the V-domain, or theta-position, for English). Consider (39):

$$
\begin{aligned}
& \text { a. Martin hat das Buch komplettgelesen. } \\
& \text { Martin has the book completely read } \\
& \text { 'Martin read the book completely.' }
\end{aligned}
$$

\section{b. * Martin hat komplett das Buch gelesen.}

*'Martin read completely the book.'

A prosodically unmarked argument may not appear to the right of manner adverbs. If these modifiers are adjoined to $v \mathrm{P}$, we have a straightforward argument for overt argument movement in German, and the fact that the landing site must precede such adverbials. Abstracting away from the adverbial position, it is unlikely that the stress pattern which marks the argument as focus directly affects syntactic movement, given that the focused element may appear in a number of positions, each arguably expressing the same truth-conditions:

(40) a. Martin hat komplett DAS BUCH gelesen, nicht die Zeitung. Martin has completely the book read not the newspaper 'Martin read THE BOOK completely, not the newspaper.'

b. Martin hat DAS BUCH komplett gelesen, nicht die Zeitung.

c. DAS BUCH hat Martin komplett gelesen, nicht die Zeitung.

Another way of capturing the facts is to say that focus may appear in default argument position in the $\mathrm{T}$-domain, in some left-peripheral position in the C-domain, or in a position where it could not appear otherwise (i.e. were it unstressed, a case I cannot discuss further).

Interestingly, under a simple-COMP approach, there would be no easy (syntactic) way to distinguish the following contrast:
a. * Kein Buch/ Wenige Bücher/ Kaum ein Buch hat Peter gelesen. no book few books barely a book has Peter read *'No book/Few books/Barely a book, Peter read.'
b. Jedes Buch/ Viele Bücher/ Die meisten Bücher hat Peter gelesen. everybook/ many books/ the most books has Peter read 'Every book/Many books/Most books, Peter read.' 
(42) a. KEIN BUCH/WENIGE BÜCHER/KAUM EIN BUCH hat Peter gelesen. 'Peter read NO BOOK/FEW BOOKS/BARELY A BOOK.'

'It was no book/few books/barely a book that Peter read.'

b. JEDES BUCH/VIELE BÜCHER/DIE MEISTEN BÜCHER hat Peter gelesen.

'Peter read EVERY BOOK/MANY BOOKS/MOST BOOKS.'

'It was every book/many books/most books that Peter read.'

We can see that some quantified expressions can be topicalized, while others cannot. In particular, decreasing quantifiers resist topicalization in both English and German, as shown in (41a), while increasing quantifiers may be topicalized, as in (41b). Naturally, this makes a lot of sense semantically, but syntactically COMP could be there in both cases. We can now capture this difference and ban TopP as a possible landing site for some elements. This has interesting consequences in other areas, which I explored in detail for multiple Wh-questions (Grohmann 1998, 1999, reanalysing a set of data first discussed by Beck 1996). Moreover, the fact that the option of fronting is not readily available to English focus, as the translations suggest, might be related to the verbal character of Foc: while it attracts the verb in German, it does not so in English, at least not in declarative contexts. By understanding the different $C$-heads to be verbal or not (in the sense used here), we might also be able to say more about the verb second nature, namely that it is really movement to the highest possible head, given that both Top and Foc are verbal. Naturally, we have already seen one C-head that does not seem to attract the verb in German: C (or Force in Rizzi 1997) in left dislocation. Further discussion must be postponed, but as the following suggests, this line of reasoning might help us further in left-peripheral constructions in other languages.

Hungarian, for example, marks focus in a special position, obviously inside the discourse-prominent C-domain (data from É. Kiss 1995:16):

$$
\begin{array}{lll}
\text { János (és Mari) } & \text { jelest } & \text { kapott. } \\
\text { John (and Mary) A+ } & \text { got } \\
\text { 'Janos and Mari got A+.' } &
\end{array}
$$

b. JÁNOS *<kapott $>$ (ÉS MARI) <kapott $>$ jelest *<kapott $>$. 'It was John and Mary who got A+.'

(43) shows us that focus fronting and verb raising go hand in hand: focusing the subject from the unmarked structure (43a) forces the inflected verb to move high up, too. The fact that it cannot split up the focused constituent, as in the coordinated variation indicated, suggests that this fronting is not PF-induced (attaching to the first word or something like that), but targets a syntactic head position. It lies near to understand this head position as the head that licenses the specifier for the fronted focus. In other words, we can (43b) to mean that focus targets SpecFocP whose head is filled by the finite verb (as in (42) in German).

If the finite verb raises in one case of focusing - and it raises high, as the contrast in (43) shows - , we expect that it always raises in focus constructions. Thus, we can assume that the verb and the focused constituent in (44) are in FocP. FocP seems to be rather high in the structure, given (43); as we can see from (44), focus is not the highest projection, though (É. Kiss 1995:17): 


$$
\begin{aligned}
& \text { A Háború és békét TOLSZTOJ írta. } \\
& \text { the War and Peace Tolstoy wrote } \\
& \text { 'It was Tolstoy who wrote War and Peace.' }
\end{aligned}
$$

In Hungarian, background information ('topic') may precede new information ('focus'). This can be accommodated by the structure that Rizzi (1997) assigns to the C-domain; under our set of assumptions we would say that TopP is parameterized to precede FocP in Hungarian (but not German, for example, as we will se shortly). This, then, also means that Hungarian is not a verb second language, and we might get some mileage out of parameterizing the verbal nature of $\mathrm{C}$-related heads.

Basque is another language that moves focused constituents, preferably high up. Etxepare (1997) distinguishes „emphatic focus“ from „contrastive focus." In the former type of construction, no material may intervene between focused element and the verbauxiliary sequence; in the latter, material may be fronted in between the two (by an operation that need not concern us here). Compare the following (adapted from Etxepare 1997:115-116):

$$
\begin{array}{lllr}
\text { a. PATATAK maite ditu Jonek. } & \text { Jon } \\
\text { potatoes } & \text { love AUX } & \text { Jon } \\
\text { 'It is potatoes that Jon loves.' } & \\
\text { b. * } & \text { PATATAK Jonek maite ditu. }
\end{array}
$$

\section{(46) a. MIKELI, ardoa ekarri diote.}

for-Mikel wine bring $\mathrm{AUX}$

'It is for Mikel that they brought wine.'

b. JONEK, ardoa ekarri du.

Jon wine bring AUX

'It is Jon that brought the wine.'

Etxepare suggests that Emphatic Focus, such as in (45), is related to illocutionary force and shows operator properties; here, we have raising from INFL (the T-domain) to COMP (the C-domain). Contrastive Focus, on the other hand, as illustrated in (46) is interpreted internal to the T-domain and shows no operator properties. While the characterization seems to be correct, the names for the two types of focus seem to be mixed up, where contrastive focus commonly refers to the type of focus that moves into the Cdomain (see É. Kiss 1998 for recent discussion). In any case, under the current approach we could integrate both moved constituents in the C-domain, one targeting a verbal projection, also correlating with Wh-movement, the other not. (Thus, Foc is verb-related in Basque, the other projection is not; it does not play a role whether this is TopP, as tacitly assumed by Etxepare (1997), or some other FP, perhaps the one argued for by Uriagereka (1995a,b) and many other authors since.)

If the CDE from (32), and the current framework in general, is on the right track, the accounts sketched here follow immediately: the focused element in Hungarian or Basque cannot move into the T-domain to check agreement features and then move on to a focus-prominent position in the same domain, but must move into the next higher $\mathrm{C}$ domain.

Vice versa, if the $\mathrm{C}$-domain relates discoursal properties to the syntactic computation in some languages, movement for that purpose is expected to target this domain. As a case in hand, consider the following (from Horvath 1995:31). 
(47)
a. Eldobtam az újságot.
away-threw-I the newspaper
'I threw the newspaper away.'
b. AZ ÚJSÁGOT dobtam el.
the newspaper threw-I away
c. * AZ ÚJSÁGOT eldobtam.
d. * Eldobtam AZ ÚJSÁGOT.

(47a) is a possible word order of subject noun phrase and verb plus particle without focusing. When the subject is focused, the finite verb must follow immediately, leaving the particle in situ, as in (47b). The contrast with (47c) shows that the particle cannot move along, or alternatively, the focused constituent must move to a specific focus position, not some possible intermediate projection allowing the verbal complex to occupy the same position as in (47a). (47d) shows clearly that the focused element has to move syntactically. In other words, if focus is marked syntactically, it must target the C-domain.

Interestingly, both Hungarian and Basque have been characterized as ,nonconfigurational" at some point (see É. Kiss 1995 and papers therein). All other things being equal, the approach laid out here could give us new clues as to how the notion of configurationality might be best understood. This section has argued for a parameterized understanding of the verbal character of some C-related heads, and the tendency has emerged that languages either place the finite verb in Foc or they do not, and the same applies to Top, independently from Foc.

\section{Conclusion}

In this article, I presented a programmatic sketch of a framework that combines earlier conceptions of clause structure (VP, INFL, COMP) with recent developments regarding finer articulated, functional structure internally (cf. Pollock 1989, Hale \& Keyser 1993, Rizzi 1997). It was necessary to abstract away from certain details (see Grohmann 2000c).

It was suggested that clauses be split into three prolific domains, areas of clause structure that are themselves made up of elaborate structure: the V-domain, licensing thematic relations, the $\mathrm{T}$-domain, licensing grammatical dependencies, and the $\mathrm{C}$ domain, licensing discoursal properties. A dynamic approach to derivations outlined here assumes the operation Spell Out to apply more than once (cf. Uriagereka 1999), modified here for each prolific domain. The articulatory-perceptual interface and the conceptualintentional interface, our pairing of sound and meaning, are mapped from the levels of PF and LF, respectively. These levels, in turn, are also dynamic in that they are fed cyclically each time a part of the syntactic derivation is spelled out.

All things being equal (and they need to be, given the lack of sufficient discussion), every XP may only occur once per prolific domain, at which point it constitutes the address for interpretation in each domain. A caveat was introduced, empirically motivated by derivational accounts of reflexivization and a variety of left dislocation, namely that an XP may move from one position to another within the same domain, just in case it spells out its copy (as a pronominal element, in general: PF-distinct from the original). I also discussed some issues relating this framework and left-peripheral phenomena across languages, noting that languages may employ discourse-relevant information to feed syntactic movement. 


\section{References}

Alexiadou, A. 1997. Adverb Placement. A Case Study in Antisymmetric Syntax. Amsterdam: John Benjamins.

Altmann, H. 1981 Formen der „Herausstellung “ im Deutschen: Rechtsversetzung, Linksversetzung, Freies Thema und verwandte Konstruktionen. Tübingen: Max Niemeyer.

Anagnostopoulou, E. 1999. Double Object Alternations and Clitic Constructions. Ms., University of Crete, Rethymnon.

Anagnostopoulou, E., H. van Riemsdijk \& F. Zwarts, eds. 1997. Materials on Left Dislocation. Amsterdam: John Benjamins.

Baker, M. 1988. Incorporation. Chicago: University of Chicago Press.

Beck, S. 1996. Quantified Structures as Barriers for LF-Movement. Natural Language Semantics 4, 1-56.

Beghelli, F. \& T. Stowell. 1997. Distributivity and Negation: The Syntax of each and every. In A. Szablocsi (ed.). Ways of Scope Taking. Dordrecht: Kluwer, 71-107.

Birner, B.J. \& G. Ward. 1998. Information Status and Noncanonical Word Order. Amsterdam: John Benjamins.

Bobaljik, J.D. \& D. Jonas. 1996. Subject Positions and the Roles of TP. Linguistic Inquiry 27, 195-236.

Bobaljik, J.D. \& H. Thráinsson. 1998. Two Heads Aren't Always Better than One. Syntax 1, 37-71.

Boeckx, C. 1999a. Decomposing French Questions. In J. Alexander, N.-R. Han \& M.M. Fox, eds. Proceedings of the $23 r d$ Annual Penn Linguistics Colloquium. University of Pennsylvania Working Papers in Linguistics 6 . Philadelphia, Penn.: Department of Linguistics, 69-80.

Boeckx, C. 1999b. Extractions. Ms., University of Connecticut, Storrs.

Boskovic, Z. 1994. D-Structure, Theta Criterion and Movement into Theta Positions. Linguistic Analysis 24, 247-286.

Boskovic, Z. 1998. On the Interpretation of Multiple Questions. Chomsky Celebration Website. http://mitpress.mit.edu/celebration.

Boskovic, Z. \& D. Takahashi. 1998. Scrambling and Last Resort. Linguistic Inquiry 29, 347-366.

Büring, D. 1997. The 59th Street Bridge Accent. London: Routledge.

Cardinaletti, A. \& I. Roberts. 1991. Clause Structure and X-Second. Ms., University of Venice \& University of Wales, Bangor.

Castillo, J.C., J. Drury \& K.K. Grohmann. 1999. Merge Over Move and the Extended Projection Principle. In S. Aoshima, J. Drury \& T. Neuvonen, eds. University of Maryland Working Papers in Linguistics 8. University of Maryland, College Park: Department of Linguistics, 63-103.

Cheng, L.L.-S. 1991. On the Typology of Wh-Questions. Doctoral dissertation, Massachusetts Institute of Technology, Cambridge.

Chomsky, N. 1977. On Wh-Movement. In P. Culicover, T. Wasow \& A. Akmajian, eds. Formal Syntax. New York: Academic Press, 71-132.

Chomsky, N. 1981. Lectures on Government and Binding. Dordrecht: Foris.

Chomsky, N. 1986. Knowledge of Language. Its Nature, Origin, and Use. New York: Praeger.

Chomsky, N. 1991. Some Notes on Economy of Derivation and Representation. In R. Freidin, ed. Principles and Parameters in Generative Grammar. Cambridge, Mass.: MIT Press, 417-454.

Chomsky, N. 1993. A Minimalist Program for Linguistic Theory. In K. Hale \& S.J. Keyser, eds. The View from Building 20. Essays in Honor of Sylvain Bromberger. Cambridge, Mass.: MIT Press, 1-52.

Chomsky, N. 1995. The Minimalist Program. Cambridge, Mass.: MIT Press.

Chomsky, N, 1998a. Minimalist Inquiries: The Framework. MIT Occasional Papers in Linguistics 15. Cambridge, Mass.: MITWPL. To appear in R. Martin, D. Michaels \& J. Uriagereka, eds. Step by Step. Cambridge, Mass.: MIT Press.

Chomsky, N. 1998b. Some Observations on Economy in Grammar. In P. Barbosa, D. Fox, P. Hagstrom, M. McGinnis \& D. Pesetsky, eds. Is the Best Good Enough? Optimality and Competition in Syntax. Cambridge, Mass.: MITWPL and MIT Press, 115-127.

Chomsky, N. 1999. Derivation by Phase. MIT Occasional Papers in Linguistics 18. Cambridge, Mass.: MITWPL.

Cinque, G. 1999. Adverbs and the Universal Hierarchy of Functional Projections. Oxford: Oxford University Press.

Citko, B. \& K.K. Grohmann. 2000. A New Argument in Favour of a Syntactic Focus Projection. Paper presented at the Focus Workshop of GLOW 23, University of Deusto, Bilbao. April 19, 2000.

Corver, N. \& H. van Riemsdijk, eds. 1994. Studies in Scrambling. Berlin: Mouton de Gruyter.

Dowty, D.R. 1991. Thematic Proto-Roles, Argument Selection, and Lexical Semantic Defaults. Language $67,547-619$.

Emonds, J.P. 1970. Root and Structure-Preserving Transformations. Doctoral dissertation, Massachusetts Institute of Technology, Cambridge.

Enç, M. 1987. Anchoring Conditions for Tense. Linguistic Inquiry 18, 633-657. 
Ernst, T. 1984. Towards an Integrated Theory of Adverb Positions in English. Doctoral dissertation, University of Indiana, Bloomington.

Ernst, T. forthcoming. The Syntax of Adjuncts. Cambridge: Cambridge University Press.

Erteschik-Shir, N. 1998. The Dynamics of Focus Structure. Cambridge: Cambridge University Press.

Etxepare, R. 1997. Two Types of Focus in Basque. In B. Agbayani \& S.-W. Tang (eds.). Proceedings of the 15th West Coast Conference on Formal Linguistics, 113-127. Stanford: CSLI. Distributed by Cambridge: Cambridge University Press.

Fox, D. 1999. Reconstruction, Binding Theory, and the Interpretation of Chains. Linguistic Inquiry 30, 157-196.

Grabski, M. \& W. Frey. 2000. Inkrementeller Aufbau und Wechsel von Diskurstopiks: Zur Steuerung der Diskursstruktur durch lexikonbasierte Information. Part P10 of DFG-Projektantrag, Zentrum für allgemeine Sprachwissenschaft, Typologie und Universalienforschung, Berlin.

Grohmann, K.K. 1996. Some Remarks on the West Germanic Mittelfeld: Scrambling, Case and Pronominalization. BA Honours thesis, University of Wales, Bangor. Revised version appeared as Pronouns and the Left Periphery of West Germanic Embedded Clauses. In W. Abraham \& E. van Gelderen, eds. German: Syntactic Problems - Problematic Syntax. Tübingen: Niemeyer, 163-189.

Grohmann, K.K. 1997. On Left Dislocation. Groninger Arbeiten zur germanistischen Linguistik 40, 1-33.

Grohmann, K.K. 1998. Syntactic Inquiries into Discourse Restrictions on Multiple Interrogatives. Groninger Arbeiten zur germanistischen Linguistik 42, 1-60.

Grohmann, K.K. 1999. German Is a Multiple Wh-Fronting Language! Paper presented at Colloque de syntaxe et sémantique à Paris 3. Université VII/Jussieu, Paris. October 7-9, 1999.

Grohmann, K.K. 2000a. Contrastive Left Dislocation, Reconstruction and Movement. Paper presented at the West Coast Conference on Formal Linguistics XIX, University of California, Los Angeles. February $4-6,2000$.

Grohmann, K.K. 2000b. A Movement Approach to Contrastive Left Dislocation. Rivista di Grammatica Generativa 24.

Grohmann, K.K. 2000c. Prolific Peripheries: A Radical View from the Left. Doctoral dissertation, University of Maryland, College Park.

Grohmann, K.K. In press. Towards a Syntactic Understanding of Prosodically Reduced Pronouns. Theoretical Linguistics 25.2/3, 149-184.

Grohmann, K.K. \& R. Etxepare. To appear. Root Infinitives: A Comparative View. Probus.

Grohmann, K.K., J. Drury \& J.C. Castillo. 2000. No More EPP. Paper presented at the West Coast Conference on Formal Linguistics XIX, University of California, Los Angeles. February 4-6, 2000.

Gundel, J.K. 1974. The Role of Topic and Comment in Linguistic Theory. Doctoral dissertation, University of Texas, Austin. Reproduced 1977. Bloomington, Ind.: Indiana University Linguistics Club.

van Haaften, T., R. Smits \& J. Vat. 1983. Left Dislocation, Connectedness and Reconstruction. In W. Abraham, ed. On the Formal Syntax of the Westgermania. Amsterdam: John Benjamins, 133-154.

Haeberli, E. 1995. Morphological Case, pro and Word Order. Ms., University of Geneva.

Hagstrom, P. 1998. Decomposing Questions. Doctoral dissertation, Massachusetts Institute of Technology, Cambridge.

Haider, H. 1990. Topicalization and Other Puzzles of German Syntax. In G. Grewendorf \& W. Sternefeld (eds.). Scrambling and Barriers. Amsterdam: John Benjamins, 93-112.

Haider, H. 1993. Deutsche Syntax - Generativ. Tübingen: Narr.

Hale, K. 1983. Walpiri and the Grammar of Non-configurational Languages. Natural Languages and Linguistic Theory 1, 5-47.

Hale, K. \& S.J. Keyser. 1993. On Argument Structure and the Lexical Expression of Grammatical Relations. In K. Hale \& S.J. Keyser, eds. The View from Building 20. Essays in Honor of Sylvain Bromberger. Cambridge, Mass.: MIT Press, 53-110.

Hornstein, N. 1995. Logical Form. From GB to Minimalism. Oxford: Blackwell.

Hornstein, N. 1998. Movement and Chains. Syntax 1, 99-127.

Hornstein, N. 1999. Movement and Control. Linguistic Inquiry 30, 69-96.

Hornstein, N. In press. Move! A Minimalist Theory of Construal. Oxford: Blackwell.

Horvath, J. 1995. Structural Focus, Structural Case, and the Notion of Feature-Assignment. In K. É. Kiss, ed. Discourse Configurational Languages. Oxford: Oxford University Press, 28-64.

Huang, C.-T.J. 1982. Logical Relations in Chinese and the Theory of Grammar. Doctoral dissertation, Massachusetts Institute of Technology, Cambridge.

Jackendoff, R. 1972. Semantic Interpretation in Generative Grammar. Cambridge, Mass.: MIT Press.

Kayne, R.S. 1994. The Antisymmetry of Syntax. Cambridge, Mass.: MIT Press.

É. Kiss, K. 1995. Introduction. In K. É. Kiss, ed. Discourse Configurational Languages. Oxford: Oxford University Press, 3-27.

É. Kiss, K. 1998. Identification Focus versus Information Focus. Language 74, 245-273.

Koizumi, M. 1994. Layered Specifiers. In M. Gonzàles, ed. Proceedings of NELS 24, Vol. 1. University of Massachusetts, Amherst: GLSA, 255-269. 
Koopman, H. \& D. Sportiche. 1982. Variables and the Bijection Principle. The Linguistic Review 2, 139160 .

Lambrecht, K. 1994, Information Structure and Sentence Form. Cambridge: Cambridge University Press.

Larson, R.K. 1988. On the Double Object Construction. Linguistic Inquiry 19, 335-392.

Lasnik, H. 1995. Last Resort and Attract F. In L. Gabriele, D. Hardison \& R. Westmoreland, eds. Proceedings of the Sixth Annual Meeting of the Formal Linguistics Society of Mid-America. Bloomington, Ind.: Indiana University Linguistics Club, 62-81.

Lasnik, H. 1999. Minimalist Analysis. Oxford: Blackwell.

Lasnik, H. \& M. Saito. 1992. Move $\alpha$ Conditions on Its Applications and Outputs. Cambridge, Mass.: MIT Press.

Lees, R. \& E. Klima. 1963. Rules for English Pronominalization. Language 39, 17-28.

Lidz, J. \& W.J. Idsardi. 1998. Chains and Phono-Logical Form. In A. Dimitriadis, H. Lee, C. Moisset \& A. Williams, eds. Proceedings of the 22nd Annual Penn Linguistics Colloquium. University of Pennsylvania Working Papers in Linguistics 6. Philadelphia, Penn.: Department of Linguistics, 109-125.

Manzini, M.R. \& A. Roussou. 2000. A Minimalist Theory of A-Movement and Control. Lingua.

Marantz, A. 1984. The Nature of Grammatical Relations. Cambridge, Mass.: MIT Press.

Marantz, A. 1993. Implications of Asymmetries in Double Object Constructions. In S. Mchombo, ed. Theoretical Aspects of Bantu Grammar I. Stanford: CSLI, 113-150.

Moro, A. 1989. There/Ci as raised Predicates. Ms., Massachusetts Institute of Technology, Cambridge.

Moro, A. 1997. The Raising of Predicates. Cambridge: Cambridge University Press.

Müller, G. 1995. A-bar Syntax. Berlin: Mouton de Gruyter.

Müller, G. \& W. Sternefeld. 1993. Improper Movement and Unambiguous Binding. Linguistic Inquiry 24, 461-507.

Nunes, J. 1995. The Copy Theory of Movement and Linearization of Chains in Minimalist Program. Doctoral dissertation, University of Maryland, College Park.

Nunes, J. 1999. Linearization of Chains and Phonetic Realization of Chain Links. In S.D. Epstein \& N. Hornstein (eds.). Working Minimalism. Cambridge, Mass.: MIT Press, 217-249.

Platzack, C. 1998. A Visibility Condition for the C-domain. Scandinavian Working Papers in Linguistics 61, 53-99.

Platzack, C. In press. Multiple Interfaces. In U. Nikanne \& E. van der Zee, eds. Conceptual Structure and Its Interfaces with Other Modules of Representation. Oxford: Oxford University Press.

Pollock, J.-Y. 1989. Verb Movement, UG and the Structure of IP. Linguistic Inquiry 20, 365-424.

Postal, P. 1971. Cross-over Phenomena. New York: Holt, Rinehart and Winston.

Prince, E. 1998. On the Limits of Syntax, with Reference to Left-Dislocation and Topicalization. In P. Culicover \& L. McNally, eds. The Limits of Syntax. New York: Academic Press, 281-302.

Richards, N.W. 1997. What Moves Where When in Which Language? Doctoral dissertation, Massachusetts Institute of Technology, Cambridge.

van Riemsdijk, H. 1997. Left Dislocation. In Anagnostopoulou et al. 1997, 1-10.

van Riemsdijk, H. \& F. Zwarts. 1974. Left Dislocation in Dutch and Status of Copying Rules. Manuscript, Massachusetts Institute of Technology, Cambridge \& University of Amsterdam. Originally published in Anagnostopoulou et al. 1997, 13-29.

Rizzi, L. 1996. Residual Verb Second and the Wh-Criterion. In A. Belletti \& L. Rizzi, eds. Parameters and Functional Heads. Essays in Comparative Syntax. Oxford: Oxford University Press, 63-90.

Rizzi, L. 1997. The Fine Structure of the Left Periphery. In L. Haegeman, ed. Elements of Grammar: Handbook of Generative Syntax. Dordrecht: Kluwer, 281-337.

Ross, J.R. 1967. Constraints on Variables in Syntax. Doctoral dissertation, Massachusetts Institute of Technology, Cambridge. Appeared as Ross (1986). Infinite Syntax! Norwood: Ablex.

Stepanov, A. 1999. Late Adjunction and Minimalist Phrase Structure. Ms., University of Connecticut, Storrs.

Stepanov, A. 2000. Extractability, CED and Word Order. Paper presented at the 24th Penn Linguistics Colloquium, University of Pennsylvania, Philadelphia. February 26-27, 2000.

Thráinsson, H. 1979. On Complementation in Icelandic. Doctoral dissertation, Harvard University. Also appeared with New York: Garland Publishing.

Ura, Hiroyuki. 1994. Varieties of Raising and the Feature-Based Bare Phrase Structure Theory. MIT Occasional Papers in Linguistics 7. Cambridge: MITWPL.

Ura, H. 1996. Multiple Feature-Checking: A Theory of Grammatical Function Splitting. Doctoral dissertation, Massachusetts Institute of Technology, Cambridge.

Uriagereka, J. 1995a. Aspects of the Syntax of Clitic Placement in Western Romance. Linguistic Inquiry 26, 79-123.

Uriagereka, J. 1995b. An F Position in Western Romance. In K. È. Kiss (ed.). Discourse Configurational Languages. Oxford: Oxford University Press, 153-175.

Uriagereka, J. 1999. Multiple Spell Out. In S.D. Epstein \& N. Hornstein, eds. Working Minimalism. Cambridge, Mass.: MIT Press, 251-282. 
Uriagereka, J. \& R. Martin. 1999. Lectures on Dynamic Syntax. Ms., University of Maryland, College Park \& Kanda University of International Studies.

Vallduví, E. 1992. The Informational Component. New York: Garland.

Vat, J. 1981. Left Dislocation, Connectedness and Reconstruction. Groninger Arbeiten zur germanistischen Linguistik 20, 80-103. Reprinted in Anagnostopoulou et al. 1997, 67-92.

Wasow, T. 1972. Anaphoric Relations in English. Doctoral dissertation, Massachusetts Institute of Technology, Cambridge.

Wu, J. 1996. Wh-Topic, Wh-Focus and Wh-In situ. In J.C. Castillo, V. Miglio \& J. Musolino, eds. University of Maryland Working Papers in Linguistics 4. University of Maryland, College Park: Department of Linguistics, 173-192.

Zubizaretta, M.L. 1998. Prosody, Focus and Word Order. Cambridge, Mass.: MIT Press.

Zwart, C.J.-W. 1991. Clitics in Dutch: Evidence for the Position of INFL. Groninger Arbeiten zur germanistischen Linguistik 33, 71-92.

Zwart, C.J.-W. 1993. Dutch Syntax. A Minimalist Approach. Doctoral dissertation, University of Groningen.

Zwart, C.J.-W. 1997a. The Morphosyntax of Verb Movement. The Syntax of Dutch. Dordrecht: Kluwer.

Zwart, C.J.-W. 1997b. Transitive Expletive Constructions and the Evidence Supporting the Multiple Specifier Hypothesis. In W. Abraham \& E. van Gelderen, eds. Problemsyntax Deutsch - Problem Syntax German. Tübingen: Niemeyer, 105-134.

Zwart, C.J.-W. 2000. An Argument against Multiple Specifiers. Paper presented at the West Coast Conference on Formal Linguistics XIX, University of California, Los Angeles. February 4-6, 2000. 